\title{
The Cost of Being Different: Peer Firm Costs of Cash Holdings
}

\author{
by \\ Einar C. Kjenstad \\ Submitted in Partial Fulfillment of the \\ Requirements for the Degree \\ Doctor of Philosophy
}

Supervised by

Professor Ron Kaniel

Business Administration

Simon School of Business

University of Rochester

Rochester, New York 


\section{Table of Contents}

Biographical Sketch $\quad$ iv

Acknowledgments $\quad$ v

$\begin{array}{lll}\text { Abstract } & \text { vi }\end{array}$

Contributors and Funding Sources vii

List of Tables $\quad$ viii

List of Figures $\quad$ ix

1 Introduction 1

2 Theoretical Framework 9

2.1 The Model Setting . . . . . . . . . . . . . . . . 9

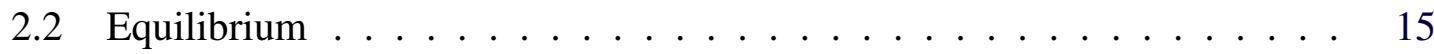


3 Data and Empirical Implementation $\quad 17$

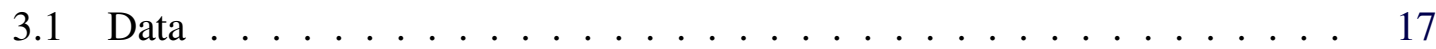

3.2 Empirical Implementation $\ldots \ldots . \ldots . \ldots$

4 Estimation Results 33

4.1 Policy Functions and State Transitions . . . . . . . . . . . . . . . 33

4.2 Main Estimation Results from Model with Peer Group Shocks to Cash Holding Incentives . . . . . . . . . . . . . . . . . 37

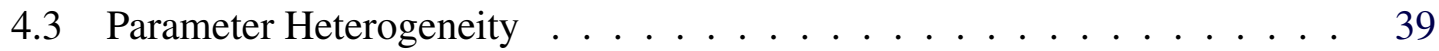

4.4 Sensitivity to the Cost of Investment . . . . . . . . . . . . . . 41

4.5 Sensitivity to the Cost of External Finance . . . . . . . . . . . . . . . 41

4.6 Results from Alternative Identification Strategies . . . . . . . . . . . . 42

4.7 Interpreting the Magnitude of Peer Effects . . . . . . . . . . . . . . . 45

5 Conclusion $\quad 48$

Bibliography $\quad \mathbf{5 0}$ 


\section{Biographical Sketch}

Einar Cathrinus Kjenstad was born in Snaasa, Norway. He attended Trondhiem Business School, where he obtained Bachelor of Business Administration degree with a concentration in Financial Management (2006), and the Norwegian School of Economics, where he obtained a Master of Science degree in Economics and Business Administration with a concentration in Financial Economics (2008). He enrolled in the doctoral program of the Simon Business School at the University of Rochester in 2011. Einar's research focused on empirical corporate finance and was conducted under the supervision of Professor Ron Kaniel. He was awarded a doctoral student fellowship from Simon Business School (2011 to 2015), a PhD Scholarship from the Norwegian Finance Initiative by Norges Bank Investment Management (2012 to 2015), and earned a Master of Science degree in Business Administration from Simon in 2014. 


\section{Acknowledgments}

I am grateful for the invaluable guidance and support I have received from my advisor Ron Kaniel and committee members Paul B. Ellickson and Erin E. Smith. I also appreciate helpful comments from Jim Brickley, Olga Itenberg, Robert Ready, Bill Schwert, Yaron Shaposhnik, Tommy Stamland, Harry Stern, Jerry Warner, Toni M. Whited, Chenyu Yang, and seminar participants at Aarhus University, the Federal Reserve Bank of Cleveland, and the University of Rochester. Finally, I would like to thank the Simon Business School and Norges Bank Investment Management for financial support. 


\section{Abstract}

I estimate a dynamic game where firms make external financing decisions and hold cash taking into account the corresponding behavior of their peers. A key advantage of this approach is that I can obtain an empirical measure of peer effects that stem from decision makers' dynamic optimization problem. Using the product market to identify peer groups, I quantify the costs associated with deviating from average industry policies. Firms' cash holdings reveal a significant negative value attached to falling below the peer group median cash-to-capital ratio. Firms with more complex information environments and firms that rely less on $\mathrm{R} \& \mathrm{D}$ in their business model put relatively larger emphasis on peer firms in their decision making. 


\section{Contributors and Funding Sources}

The work in this dissertation has been conducted independently under the supervision of Professor Ron Kaniel (advisor), Professor Paul B. Ellickson, and Professor Erin E. Smith of the Simon Business School. Graduate study was supported by a doctoral student fellowship from the Simon Business School, and a PhD Scholarship from the Norwegian Finance Initiative, est. by Norges Bank Investment Management. 


\section{List of Tables}

1 Summary statistics . . . . . . . . . . . . . . . 58

2 Determinants of the Persistence of Cash Incentive Shocks … . . . 59

3 Predictions Based on Estimated Policy Functions _ . . . . . . . . . . 60

4 Structural Parameter Estimates: Preliminary Specification . . . . . . 61

5 Structural Parameter Estimates: Main Specification _ . . . . . . . 62

6 Structural Parameter Estimates: Parameter Heterogeneity . . . . . . 63

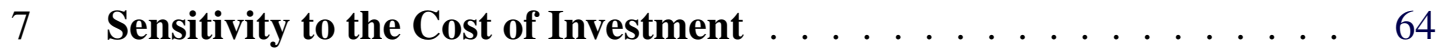

8 Sensitivity to the Cost of External Finance f . . . . . . . . . 65

9 Structural Parameter Estimates Based on Data Not Explained by Common Cross-Sectional Determinants of Cash Holdings . . . . . . . . 66

10 Structural Parameter Estimates Identified by the Assumption that Peer Effects Are Time-Invariant . . . . . . . . . . . . . . . . . . 67

11 Interpreting the Magnitude of Peer Effects $\ldots \ldots \ldots$ 


\section{List of Figures}

1 Kernel-Weighted Local Polynomial Regression of Marginal Values of Cash on Time $\ldots \ldots \ldots$

2 Persistence of Cash Incentive Shocks _ . . . . . . . . . . . . . 70

3 Policy Function for Investment . . . . . . . . . . . . . . . . . 71

4 Policy Function for External Finance . . . . . . . . . . . . . . . 72

5 An Example of the Response to Shocks to Peer Cash Holdings . . . . 73 


\section{Introduction}

How important are peer effects for corporate decision making? Firms do business and finance their activities as part of a diverse set of stakeholder relationships, manifesting the importance of understanding the empirical relevance of such interrelations in corporate policies. If firms optimize with their peers in mind, this system of interrelations will be important for the interpretation of observed data. In the context of firm financial decisions, Leary and Roberts (2014) focus on establishing a role for actions undertaken by peer firms as part of financial objectives, as well as quantitatively examine peer group externalities in choice of leverage. In this paper, I explicitly incorporate such strategic interactions in estimating a game of imperfect information in order to evaluate the importance of peer firm policies in cash holdings from the perspective of firms as decision makers. Estimation results suggest that firms account for the actions of their peers when setting optimal cash policies, evident from the substantial cost a typical firm assigns to every percentage point it falls behind the peer group median cash holdings. Firms behave as if every incremental percentage point they are below the peer group median cash holdings is associated with a cost approximately equal to a 1 percentage loss in operating income, or 0.2 percent of the firms capital. This figure is consistent across identification strategies, with the most con- 
servative estimate approximately equal to a corresponding 0.5 percentage loss in operating income. This cost is larger when firms are associated with higher information asymmetry, or when firms have lower R\&D spending. In particular, for firms in industries with high (low) information asymmetry this cost is $1.16 \%$ (0.94\%), while for industries with high (low) $\mathrm{R} \& \mathrm{D}$ spending the cost is $0.67 \%(1.33 \%)$.

I complement the existing literature on peer effects by quantifying the cost of deviating from peer cash policies as well as laying the foundation for counterfactual experiments within the framework of the model. Fresard (2010) show that there is a distinct effect of cash holdings on future firm performance beyond that of other firm characteristics, suggesting that peer effects in cash policies will have an impact on future firm performance. In order to highlight the additional insights offered by the approach taken in this paper, it is instructive to consider the methods used in light of natural alternative approaches. One way to gauge the importance of peer effects would be to estimate regressions with firm value/abnormal returns as dependent variables and cash holdings/changes in cash holdings as explanatory variables. Similarly, one could estimate the impact of peer firm characteristics and policies on firm characteristics and policies. Both approaches could be implemented using instrumental variables and other quasi-experimental approaches to further strengthen evidence of causality, and both approaches yield economically interesting and important quantities. However, my research questions motivate a slightly different empirical approach. In associating cash holdings, whether relative to peers or not, with market value the emphasis is on how equity holders value their claim to a company's cash flow, and in particular how this valuation depends on firms' cash policies. I am, on the other hand, interested in how firms as decision makers evaluate their relative position to peer when they make decisions. ${ }^{1}$ Although equity holders influence corporate actions

\footnotetext{
${ }^{1}$ Note that I will refer to firms and managers interchangeably in terms of the model. I am not able to obtain the preference parameters of firm managers in their joint optimization of firm and personal labor
} 
through their valuation of firm equity and impact on corporate governance more generally, focusing on the decision making entity explicitly is beneficial in that it captures peer effects from the broadest set of potential channels. Furthermore, the influence of peers on decision makers is completely characterized by how costly they experience discrepancies from peers, a quantity that is unobservable and difficult to estimate directly from prices or returns. However, with an economic model and in particular a specification of managerial utility, it is possible to quantify the magnitude of peer effects from the perspective of firm decision makers. If managers indeed tend to prefer cash policies that mimic their peers, this will lead firms to choose cash holdings more uniformly. Hence, another test aimed at understanding peer effects in cash holdings would be to estimate how peer firm actions influence firm actions. This achieves a description of how firms choose their cash holdings as a function of peer firm actions. However, my research questions relate to the deeper preference of managers, which is not immediate from such a framework. In fact, the estimated quantities in this paper can be seen as an interpretation of observed behavior, for example as represented by regression analyses relating firms' cash holdings to each other, in light of the model framework. In particular, it is the notion that observed policies are optimal and thus better than plausible alternatives that is the key assumption allowing for identification of peer effects as defined by the cost of deviation from peers, and it is precisely the nature of this basic firm characteristic that is the focus of this study. However, in general identification is established by assumptions and the assumptions here are different than that of the alternative approaches indicated above. The model is the instrument through which data is summarized by a set of structural parameters. If the model is an inadequate representation of firms, this will be reflected in the estimated parameters.

decisions. Rather, I am interested in the preferences underlying observed decisions made by firms. One can therefore think of the estimated parameters characterizing the preferences and constraints of a representative agent, determined by the influence of all relevant stakeholders. 
Key among such concerns are omitted state variables; an issue I explicitly address in the estimation.

The relative importance of the governing forces through which peer effects arise is theoretically and empirically challenging to evaluate. In a situation of imperfect competition it is not a priori clear how interrelations in product market strategies will influence other corporate policies, nor vice versa. For example, Bolton and Scharfstein (1990) show that asymmetric financial flexibility might induce predatory strategies by rival firms, while Brander and Lewis (1986) demonstrate how financial policies can be commitment mechanisms for product market strategies. ${ }^{2}$ The idea that competition over future investment opportunities might also induce firms to hold similar cash levels is conceptually similar to e.g. DeMarzo et al. (2007) who show that, due to relative wealth concerns stemming from future competition over scarce resources, investment in new technology might be excessive (see also DeMarzo et al. (2008, 2004)). Furthermore, frictions such as imperfect information will not only alter competitive equilibria but likely induce similar effects in its own right. Prominently, managers unsure in characterizing optimal actions can observe firms facing similar challenges to learn about how their peers evaluate business conditions and form associated firm policies, and firms that seek to reduce information asymmetry by altering the financial market perception of their true state have to be concerned about their rank in the set of firms under consideration. I will rely on this intuitive notion in the framework applied in this paper, while Grenadier et al. (2014) formally show how mimicking in investment abandonment decisions arise optimally due to asymmetric information. In particular, in a real options model where common shocks force termination of projects irrespective of quality, there are gains to postpone abandonment to an informationally less revealing environment. Another rigorous treatment of imitation in a dynamic model can

\footnotetext{
${ }^{2}$ Chevalier and Scharfstein (1996) also study how asymmetries in financial flexibility can affect relative performance in the product market.
} 
be found in Conlisk (1980). ${ }^{3}$

The main contribution of this study is an investigation of the relevance of peer effects in corporate decision making; in particular for corporate cash holdings, and is therefore closely related to Leary and Roberts (2014) who perform a conceptually similar analysis of firm capital structure, emphasizing the importance of future corporate finance research explicitly recognizing firm interactions; Francis et al. (2016) who provide international evidence on importance of peer effects in leverage decisions, highlighting the role of investor protection laws, creditor rights laws and equity market development in shaping peer influende; Kaustia and Rantala (2015) who show that firms have a propensity to split their stock that is increasing in peer firm stock split events and associated announcement returns; Popadak (2017) who find that peer effects have a positive influence on dividend payments and negative effect on the time to dividend changes; and Chen and Chang (2012) who apply the Leary and Roberts (2014) identification strategy to study cash holdings. The research questions of this study are distinct from the latter in focusing on quantifying the costs firms assign to being different from their peers as a basis for understanding peer effects, made possible by estimating a dynamic game of imperfect information. An additional benefit is the possibility of doing counterfactual analyses experiments where firm behavior with and without peer effects can be compared.

There is a large literature studying the determinants of corporate cash holdings and the overall time series pattern of cash holdings, see e.g. Bates et al. (2009); Harford et al. (2008); Opler et al. (1999). A key strand of the existing cash holdings literature relating to peer effects are studies of product markets and cash holdings. Introducing the new measure fluidity of product market threats, taking the form of the intro-relative movement by competitors in product space, Hoberg et al. (2014) find that cash holdings are higher for firms

\footnotetext{
${ }^{3}$ In Scharfstein and Stein (1990) mimicking in investment arises due to labor market concerns stemming from perceived managerial ability determining compensation and being dependent on relative performance.
} 
facing higher product market threats. Morellec et al. (2013) emphasize the importance of financing constraints in the relation between competition and cash holdings. Focusing on predation risk, Haushalter et al. (2007) find that firms manage predation risk by holding more cash while Chi and $\mathrm{Su}$ (2016) show that corporate cash holdings are more valuable when predation risk is higher. Larkin (2013) finds that firms with comeptitive advantages in the form of stronger brand value hold relatively less cash. Using instrumental variables and a natural experiment, Fresard (2010) focus on the ex post effects of cash holdings and establish an effect of cash holdings on future product market performance. The role of peer groups in determining optimal cash policies is also recognized in other studies where the primary focus is not peer effects per se. One example is Harford (1999), who estimate "normal" cash holdings using panel regressions estimated on samples split by industries in order to account for the differences in cash policies across industries. New to the above literature is my investigation of the significance of firm interrelations in corporate decision making in a framework that allows for a quantification of how important peer actions are for cash holdings.

Similarly, proxies for information asymmetry are common in studies of cash policies due to the prominence of information related friction in understanding corporate finance (e.g. Opler et al., 1999). Studies with an explicit main focus on information asymmetry include e.g. Drobetz et al. (2010), who in a cross-country study find that, consistent with free cash flow theory of Jensen (1986), cash holdings are valued inferiorly when information asymmetry is high. Rather than focusing on how firms' information environments are associated with cash holdings more broadly, I allow for a role of information asymmetry in establishing peer effects in corporate behavior, and study cash holdings and information asymmetry from the perspective of interrelated decision making.

This study is also related to Jiang and Lie (2016), who investigate the speed of adjust- 
ment of cash holdings. Jiang and Lie (2016) find that firms annually eliminates $31 \%$ of the distance to optimal cash holdings, a number that is higher for firms with excess cash but decreasingly so when firms experience reduced takeover threats, supportive of managerial entrenchment as a source of cash stockpiling. My analysis is centered around peer firm cash holdings as a references point for optimal cash policy, and differs from Jiang and Lie (2016) in that the emphasis is not on a speed of adjustment per se.

Dynamic models have been used to illuminate several aspects of corporate cash policy. Whited (2006) introduces cash savings to study how external finance constraints affect the likelihood of initiating large investment projects. In a model where cash reduces external financing costs but cash interest is taxed, Riddick and Whited (2009) study the optimal savings policy of firms and find that, controlling for Tobin's q, saving and cash flow are negatively related, which is further confirmed in their empirical analysis. Gamba and Triantis (2008) analyze the value of financial flexibility in a model where financing frictions induce joint borrowing and lending. Nikolov and Whited (2014) estimate a model incorporating agency costs, evaluate the relative importance of different agency mechanisms, and also find that lower managerial ownership and the associated misalignment of interests is an important driver of the increase in corporate cash holdings. ${ }^{4}$ Gao et al. (2016) develop a dynamic model where costs of external finance are determined by interest rates, explaining the hump-shaped relation between interest rates and cash holdings documented in the paper. Furthermore, Bakke and $\mathrm{Gu}$ (2016) analyse the cash holding decisions of conglomerates vs. standalone firms based on a structural estimation of a dynamic investment model, while Gu (2016) focus on the cash holding differential associated with firms having overseas activities. New to this literature is my attempt at estimating a model where there are inter-firm strategic components to cash holdings, as suggested by Strebulaev and

\footnotetext{
${ }^{4}$ See also Anderson and Carverhill (2012), Eisfeldt and Muir (2016), Hugonnier et al. (2014), Kisser (2013), Decamps et al. (2011).
} 
Whited (2012) and also proposed by Leary and Roberts (2014). To the best of my knowledge, this is the first structural estimation of a dynamic game with emphasis on corporate financial decision-making based on non-experimental data, implemented using estimators originating from empirical industrial organization. In particular, I apply the Bajari et al. (2007) two-step estimator, making the computational challenges manageable while also allowing for continuous choice variables. 


\section{Theoretical Framework}

The purpose of this paper is to evaluate the importance of peer effects in cash holding decisions, and additionally to determine which underlying mechanisms are causing this feature of corporate decision making. This is accomplished by estimating a model where firms noncooperatively make simultaneous investment and financing decisions, facing non-pecuniary costs of deviating from peer firms along the dimensions of cash holdings. The choice of a simultaneous move game has important implications for the interpretation of the results, e.g. will learning only enter through dynamic behavior over several time periods, consistent with the reduced form modeling choice of strategic behavior. In this section I describe the basic framework that will be the foundation of the subsequent estimation.

\subsection{The Model Setting}

The basic agents of the model are firms making investment and external financing decisions, using cash a storage technology allowing cash flows to be saved for later investment use. Each firm is equipped with a set of peer firms, forming transitive peer groups that 
are exogenously given and constant over time, i.e. there is no entry or exit. There are $N_{j, t}$ firms in peer group $j$ at time $t$, indexed by $i_{t}^{j}$. Time is discrete in an infinite-horizon setting. Firm $i_{t}^{j}$ faces productivity $z_{i, t}^{j} \in\left[0, \bar{z}^{j}\right]$ generating cash flows $z_{i, t}^{j} k_{i, t}^{j}$, where $k_{i, t}^{j}$ is the non-negative capital stock of firm $i$ in peer group $j$ at time $t$, bounded also from above by $\bar{k}^{j}$. Irreversible investment $I_{i, t-1}^{j} \in\left[0, \bar{I}^{j}\right]$ adds unit price capital to the depreciated stock $(1-\delta) k_{i, t-1}^{j}$ in generating the new capital stock $k_{i, t}^{j}$. The law of motion for profitability follows a Markov process with i.i.d. firm level shocks:

$$
\begin{aligned}
& z_{i, t}^{j}=G_{z}^{j}\left(z_{i, t-1}^{j}\right)+\epsilon_{z, i, t}^{j} \\
& \epsilon_{z, i, t}^{j} \sim N\left(0, \sigma_{z}^{j} \mid z_{i, t-1}^{j}\right)
\end{aligned}
$$

Unlike e.g. Warusawitharana (2015), who estimates a model where R\&D investment serves to stochastically alter firms' profitability processes, firms cannot alter their underlying profitability. In relying on an exogenous process as a key driving force of firm cash flows, it is clear that several aspects of firm strategy cannot be investigated in great detail, e.g the relation between cash holdings and "investment" in market shares (Chevalier and Scharfstein (1996). This modeling choice is data driven, but allows for illumination of the key mechanisms of interest to the research questions under study, consistent with profitability as observed in the data. For example, profitability will be an important consideration in firms' decisions on how much cash to save and how much to spend on capital. Investment induces the following adjustment costs:

$$
\Phi_{I}^{j}\left(I_{i, t}^{j}, k_{i, t}^{j}\right)=\mathcal{I}_{I_{i, t}^{j}>0}\left(\phi_{I, 1}^{j} K_{i, t}^{j}+\phi_{I, 2}^{j}\left(\frac{I_{i, t}^{j}}{K_{i, t}^{j}}\right)^{2}\right)
$$

where $\mathcal{I}_{A}$ is an indicator variable for condition $A$ being true. Investment can be made out of the non-negative cash stock $p_{i, t}^{j}$ or external financing $e_{i, t}^{j}$. Cash in any given period is 
the sum of cash, external finance and cash flows in the previous period:

$$
p_{i, t}^{j}=p_{i, t-1}^{j}+e_{i, t-1}^{j}+\pi_{i, t-1}^{j}
$$

where $\pi_{i, t-1}^{j}$ is cash flow defined as operating income net of investment, investment adjustment costs, cost of cash holdings and external financing costs, as specified below. The main contribution of this framework is to allow for interrelated decision making in a game between peer firms. In doing so, I follow previous literature and let managers gain utility from deviation from their peers in relevant dimensions. The cost of holding cash $p_{i, t}^{j}$ is

$$
\Phi_{p}^{j}\left(p_{i, t}^{j}, k_{i, t}^{j}, \xi_{i, t}^{j}\right)+\gamma_{p}^{j} f^{p}\left(\frac{p_{i, t}^{j}}{k_{i, t}^{j}}-\widetilde{\left(\frac{p}{k}\right)^{j}}\right)
$$

where ${\widetilde{\left(\frac{p}{k}\right)_{-i, t}^{j}}}^{j}$ is the median cash holdings of peer firms and $\xi_{i, t}^{j}$ is a state variable capturing unmodeled incentives for holding cash, which is further explained below. The parameter $\gamma_{p}^{j}$ captures the utility that firms obtain from deviating from peer group cash holding decisions through the function $f^{p}\left(\frac{p_{i, t}^{j}}{k_{i, t}^{j}}-{\widetilde{\left(\frac{p}{k}\right)_{-i, t}^{j}}}_{-j}^{j}\right.$ in any given period. The key assumption imposed here is therefor that firms compare their own cash holding states to that of the median cash holdings of their peers. $\gamma_{p}^{j}$ can also be a vector of parameters depending on the function $f^{p}(\cdot)$. The $\gamma_{p}^{j}$ parameter is, together with similar considerations for other policies, the source of strategic interaction in the model, making firm decisions interrelated. The other costs $\Phi_{p}^{j}\left(p_{i, t}^{j}, k_{i, t}^{j}, \xi_{i, t}^{j}\right)$ of cash holdings are given by:

$$
\Phi_{p}^{j}\left(p_{i, t}^{j}, k_{i, t}^{j}, \xi_{i, t}^{j}\right)=\mathcal{I}_{p_{i, t}^{j}>0}\left(\left(\phi_{p, 1}^{j} p_{i, t}^{j}\right)+\phi_{p, \xi}^{j} \xi_{i, t}^{j}\right)
$$

The added reduced form specification of the strategic costs of cash holdings finds sound motivation, along with similar considerations for external finance, in industrial organiza- 
tion, marketing and other areas of research emphasizing strategic considerations as explained above. I have opted for a reduced form specification partly because of data availability. A model incorporating endogenous pricing, quantities, entry and exit would allow for a fascinating inquiry into the details of the mechanisms at work. However, for my chosen sample such information is either missing or otherwise not satisfactorily available.

The above specification embeds active interactions resulting in underlying "social multipliers" of interrelated firm policies, also through forward looking behavior. ${ }^{1}$ In further specifications I also investigate asymmetries in these relations. Intuitively, the notion guiding methods and modeling, as captured by the above costs of deviating from peer firms, is methodologically similar to endogenous conformity from resulting preferences for adherence to social norms through utility of other agents' perceptions of oneself, as in e.g. Bernheim (1994), with the key difference that costs of deviation in this setup are meant to proxy for the value of avoiding future monetarily undesirable states. In order to allow for asymmetries in the cost of being above and below the median ratios of cash to capital in any give peer group, I use the following functional form to capture the costs of deviating:

$$
\mathcal{I}_{\left(\frac{p_{i, t}^{j}}{k_{i, t}^{j}}-\widetilde{\left(\frac{p}{k}\right)_{-i, t}^{j}}\right)>0} \gamma_{p, 1}^{j}\left|\frac{p_{i, t}^{j}}{k_{i, t}^{j}}-\widetilde{\left(\frac{p}{k}\right)^{j}}\right|+\mathcal{I}_{\left(\frac{p_{i, t}^{j}}{k_{i, t}^{j}}-\widetilde{\left(\frac{p}{k}\right)_{-i, t}^{j}}\right)_{<0}} \gamma_{p, 2}^{j}\left|\frac{p_{i, t}^{j}}{k_{i, t}^{j}}-\widetilde{\left(\frac{p}{k}\right)^{j}}{ }_{-i, t}^{j}\right|
$$

I will use $\mathcal{I}_{A}$ as shorthand notation for $\mathcal{I}_{\left(\frac{p_{i, t}^{j}}{k_{i, t}^{j}}-\widetilde{\left(\frac{p}{k}\right)_{-i, t}^{j}}\right)>0}$. The benefits of cash stem from future ability to take advantage of investment opportunities without resorting to costly external finance, which in the model framework will be beneficial in terms of relative product market performance to the extent that otherwise similarly situated peer firms cannot. This is consistent with the evidence in e.g. Fresard (2010), but without a more elaborate model of and data on competitive equilibrium, further insight into the relation between product

\footnotetext{
${ }^{1}$ See e.g. Hartmann et al. (2008) for a survey.
} 
market strategies and cash holdings, as well as the former's relative importance to the latter, is not immediate from the model. Furthermore, the emphasis here is on the relation between industry peers, and the role of cash in e.g. deterring entry (Benoit (1984) is not captured by the model. For a dynamic cash management model taking into account competition, see e.g. Morellec et al. (2013).

The main emphasis is on peer effects in cash holdings, though in robustness tests I also let external finance characterized by peer effects explicitly. Let $\widetilde{\left(\frac{e}{k}\right)}_{-i, t}^{j}$ be the median external financing activity among the peers of firm $i$. Firms achieve the following exogenous utility of deviating from the peer group average external finance:

$$
\gamma_{e}^{j} f^{e}\left(\frac{e_{i, t}^{j}}{k_{i, t}^{j}}-\widetilde{\left(\frac{e}{k}\right)_{-i, t}^{j}}\right)
$$

The total costs of raising external finance are given by:

$$
\Phi_{e}^{j}\left(e_{i, t}^{j}, k_{i, t}^{j}\right)+\gamma_{e}^{j} f^{e}\left(\frac{e_{i, t}^{j}}{k_{i, t}^{j}}-\widetilde{\left(\frac{e}{k}\right)_{-i, t}^{j}}\right)
$$

where

$$
\Phi_{e}^{j}\left(e_{i, t}^{j}, k_{i, t}^{j}\right)=\mathcal{I}_{e_{i, t}^{j}>0}\left(\phi_{e, 1}^{j} e_{i, t}^{j}\right)
$$

Since the model is targeted at understanding peer group interactions in cash holdings, the model is not adequate for capturing the heterogeneous effects in external finance components. There are also interesting interactions between prominent industrial organization notions and the composition of providers of external finance, which is the topic of Murfin and Pratt (2017), that I leave unexplored in this paper due to data availability. Similarly, competition among banks have been shown to influence cash holdings (Pinkowitz and Williamson, 2001), as well as bargaining with firm stakeholders (Klasa et al., 2009) that is 
a direct result of inter-firm strategic interaction.

Finally, $\xi_{i, t}^{j}$ is a state variable capturing unmodeled incentives for holding cash, captured by the cost parameter $\phi_{p, \xi}^{j} \cdot \xi_{i, t}^{j}$ follows a first-order Markov process with i.i.d. innovations $\eta_{i, t, t+1}^{j}$ :

$$
\xi_{i, t+1}^{j}=\mu_{t, t+1}^{j} \xi_{i, t}^{j}+\eta_{i, t, t+1}^{j}
$$

Peer group wide shocks to incentives of holding cash that are not explicitly incorporated in the model might affect the model estimates akin to the reflection problem of Manski (1993). I control for such confounding dynamics and overcome the reflection problem by construction a state variable for unobserved peer group incentives to hold cash. This is accomplished by estimating the value of cash using an approach similar to that of Faulkender and Wang (2006), and then using these values of cash to estimate the hedonic prices of other state variables (in terms of the value of cash), using the method of Bajari et al. (2012), with the purpose of estimating a time series model of the error terms of these regressions serving as estimates of unobserved peer group incentives for holding cash. Informally, this is a regression with market value of cash as the dependent variable and model state variables as explanatory variables, extended to tackle endogeneity issues as in Bajari et al. (2012). The basic idea is that the error terms of the regression capture the value of cash that is not explained by the model. It is also an underlying assumption that the market valuation of cash captures the incentives a firm has to hold cash. The Bajari et al. (2012) estimator allows unobserved peer group heterogeneity to be correlated with other observed state variables and does not impose independence over time, and this heterogeneity, represented by the constructed state variable, is subsequently used in simulating firm decisions and value. The details of the empirical implementation are given in section 3.2. 


\subsection{Equilibrium}

I now consider how the above model elements are related in establishing an equilibrium. Recall that cash flow $\pi_{i, t-1}^{j}=z_{i, t}^{j} k_{i, t}^{j}-I_{i, t}^{j}-\Phi_{I}^{j}\left(I_{i, t}^{j}, k_{i, t}^{j}\right)-\Phi_{e}^{j}\left(e_{i, t}^{j}, k_{i, t}^{j}\right)-$ $\Phi_{p}^{j}\left(p_{i, t}^{j}, k_{i, t}^{j}, \xi_{i, t}^{j}\right)$ adds to non-pecuniary costs in generating utility to the firm: $u_{i, t-1}^{j}=$ $\pi_{i, t-1}^{j}-\gamma_{e}^{j} f^{e}\left(\frac{e_{i, t}^{j}}{k_{i, t}^{j}}-\widetilde{\left(\frac{e}{k}\right)_{-i, t}^{j}}\right)-\gamma_{p}^{j} f^{p}\left(\frac{p_{i, t}^{j}}{k_{i, t}^{j}}-{\widetilde{\left(\frac{p}{k}\right)^{j}}}_{-i, t}^{j}\right)$. Firms maximize utility given the beliefs about peer group equilibrium play. I assume that the set of actions $\boldsymbol{a}_{t}^{j}=$ $\left[I_{1, t}^{j}, \ldots, I_{N_{j, t}, t}^{j}, e_{1, t}^{j}, \ldots, e_{N_{j, t}, t}^{j}\right]^{\prime}$, determined by the strategy profile $\boldsymbol{\sigma}^{j}\left(\boldsymbol{s}_{\boldsymbol{t}}\right): \boldsymbol{a}_{\boldsymbol{t}}^{j}=\boldsymbol{\sigma}^{j}\left(\boldsymbol{s}_{\boldsymbol{t}}\right)=$ $\left[\sigma_{1}^{j}\left(s_{t}\right), \ldots, \sigma_{N_{j, t}\left(s_{t}\right)}^{j}\right]^{\prime}$, are characterized by a symmetric pure Markov Perfect Nash Equilibrium. Firms observe capital and cash holdings for all peer firms, as well as their own profitability shock and innovation to the state variable for cash incentives before undertaking actions simultaneously, while the vectors $\left[\epsilon_{z, 1, t}^{j}, \ldots, \epsilon_{z, N_{j, t}, t}^{j}\right] \backslash\left[\epsilon_{z, i, t}^{j}\right]$ and $\left[\eta_{1, t}^{j}, \ldots, \eta_{N_{j, t}, t}^{j}\right] \backslash\left[\eta_{i, t}^{j}\right]$ of, respectively, profitability shocks and shocks to the state variables of cash holding incentives for other firms are observed only after investment and external finance decisions are committed. Thus the aggregate common state vector is defined as

$$
\begin{array}{r}
\boldsymbol{s}_{\boldsymbol{t}}^{j}=\left[k_{1, t}^{j}, \ldots, k_{N_{j, t}, t}^{j}, p_{1, t}^{j}, \ldots, p_{N_{j, t}, t}^{j}, G_{z}^{j}\left(z_{1, t-1}^{j}\right), \ldots\right. \\
\left.G_{z}^{j}\left(z_{N_{j, t}, t-1}^{j}\right), \mu_{t-1, t}^{j} \xi_{1, t}^{j}, \ldots, \mu_{t-1, t}^{j} \xi_{N, t-1}^{j}\right]^{\prime}
\end{array}
$$

Summarizing the time line of the model, firm $i$ observes the common state vector $s_{t}^{j}$ and its own profitability shock $\epsilon_{z, i, t}^{j}$ and $\eta_{i, t-1, t}^{j}$ before deciding how much to invest and how much external finance to raise. 
A firm has the following sum of discounted utility at state $\left\{\boldsymbol{s}, z_{i}^{j}, \xi_{i, t}^{j}\right\}$ :

$$
\begin{aligned}
& V_{i}^{j}\left(\boldsymbol{s} ; z_{i}^{j} ; \xi_{i}^{j} ; \boldsymbol{\sigma}^{j} ; \theta\right)= \\
& E\left[\sum_{t=0}^{\infty} \beta^{t} u_{i, t}^{j}\left(\boldsymbol{\sigma}^{j}\left(\boldsymbol{s}_{\boldsymbol{t}}, \boldsymbol{\epsilon}_{z, t}^{j}\right), \boldsymbol{s}_{\boldsymbol{t}}^{j}, \epsilon_{z, i, t}^{j} ; \theta\right) \mid \boldsymbol{s}_{\mathbf{0}}^{j}=\boldsymbol{s}^{j} ; z_{i, 0}^{j}=z_{i}^{j}, \xi_{i, 0}^{j}=\xi_{i}^{j} ; \theta\right]
\end{aligned}
$$

where expectations are formed over shocks $\boldsymbol{\epsilon}_{t}^{j}=\left[\epsilon_{z, 1, t}^{j}, \ldots, \epsilon_{z, N_{j, t}, t}^{j}, \eta_{1, t-1, t}^{j}, \ldots, \eta_{N, t-1, t}^{j}\right]^{\prime}$ to profitability and the state variable for unmodeled cash incentives subject to beliefs about equilibrium play and state transitions, and $\theta$ is the set of structural parameters to be estimated:

$$
\theta=\left[\gamma_{e}^{j}, \gamma_{p}^{j} \phi_{I, 1}^{j}, \phi_{I, 2}^{j}, \phi_{e, 1}^{j}, \phi_{p, 1}^{j}, \phi_{p, \xi}^{j}\right]
$$

Note that $\gamma_{e}^{j}$ and $\gamma_{p}^{j}$ are vectors of parameters implicitly defined by the functions $f^{e}(\cdot)$ and $f^{p}(\cdot)$ The equilibrium of best responses $\sigma^{j}\left(s_{t}\right)$ satisfies, for any firm $i$, state $s$ and deviating policy $\sigma_{i}^{j^{\prime}}$ combination, the following optimality condition

$$
V_{i}\left(\boldsymbol{s}^{j} ; z_{i}^{j} ; \xi_{i}^{j} ; \sigma_{i}^{j}, \boldsymbol{\sigma}_{-i}^{j} ; \theta\right) \geq V_{i}\left(\boldsymbol{s}^{j} ; z_{i}^{j} ; \xi_{i}^{j} ; \sigma_{i}^{j^{\prime}}, \boldsymbol{\sigma}_{-i}^{j} ; \theta\right)
$$

where $\sigma_{-i}^{j}\left(s_{t}\right) \equiv \sigma^{j}\left(s_{t}\right) \backslash \sigma_{i}^{j}\left(s_{t}\right)$ is the set of strategies for all firms except that of firm $i$. I assume existence but not uniqueness of equilibrium. 


\section{Data and Empirical Implementation}

In this section I first, in Section 3.1, present the data used in this study, before introducing the empirical methods used to estimate the model in Section 3.2.

\subsection{Data}

The basis of the sample is firm-year observations of manufacturing firms from the CRSPCompustat merged database covering the 1972 - 2015 period. Peer groups are identified by industries in the form of four-digit SIC codes, motivated by the relevance of product markets for peer effects, as well as the prominence of learning opportunities within industries. The choice of the peer group definition represents a tradeoff between relevance and availability of information. This industry definition allows for a longer time series compared to the recently developed alternative in the form of the intersection of firm-year observations in Compustat and the 10-K text-based fixed industry classifications data from the Hoberg-Phillips data library, allowing for more precise estimates of policy functions, as well resulting in a substantially more computationally manageable estimation implementation due to industry coarseness and transitivity. In Section 3.1.1 below I define the 
variables used in the study as well as the sample selection criteria, while in Section 1 I continue with a presentation of basic summary statistics of this sample.

\subsubsection{Variables and Sample Selection}

Using Compustat variable definitions, ${ }^{1}$ the main variables are defined as follows: Cash is CHE, Assets is AT, Capital is PPEGT, Investment is CAPX-SPPE, ExternalFinance is (DLTIS - DLTR + SSTK) - (DVC + DVP + PRSTKC), Profitability is OIBDP/PPEGT, and MCap is CSHO times PRCC. From the Hoberg-Phillips data library (Hoberg et al. (2014), Hoberg and Phillips (2010), ${ }^{2}$ Fluidity is the fluidity measure of product market threats in the form of competitors' repositioning in product space, relative to any given firm under study, while $H H I$ is the Herfindahl Hirschmann Index calculated from Compustat sales data and the above mentioned fixed industry classifications. All data is observed at annual frequencies.

The sample is further restricted by deleting any observation that is not part of a consecutive series of firm-year observations with total length of at least two years after deleting observations where Assets is less than USD two million; Capital is less than USD one million; necessary variables, including lags when relevant, are missing; and acquisitions constitute more than $15 \%$ of assets. ${ }^{3}$ I also delete any observation that is among the two percent most extreme observations in either tail for Investment, ExternalFinance and

\footnotetext{
${ }^{1}$ AT: Assets - Total; CHE: Cash and Short-Term Investments; OIBDP: Operating Income Before Depreciation; DLTIS: Long-Term Debt/Issuance; DLTR: Long-Term Debt/Reduction; SSTK: Sale of Common and Preferred Stock; CAPX: Capital Expenditures; DVC: Dividends Common/Ordinary; DVP: Dividend Preferred/Preference; PRSTKC: Purchase of Common and Preferred Stock.

${ }^{2}$ See http://cwis.usc.edu/projects/industrydata/.

${ }^{3}$ For sample selection purposes, level variables are measured in 2015 dollars using the (all item) Consumer Price Index for All Urban Consumers, obtained from The Federal Reserve Bank of St. Louis Economic Data available at https://research.stlouisfed.org/fred2/
} 
Profitability, as well as observations having the $2 \%$ highest values of Cash, resulting in a sample of 16094 firm-year observations for 2386 firms in 109 peer groups.

\subsubsection{Summary Statistics}

Summary statistics are given in Table 1. From the full sample statistics in Panel A we find that the median book value of Capital is 111 million, which is higher than the full Compustat database for manufacturing firms during the corresponding time period. The mean book value of Capital of more than 2 billion is also larger for my sample. A similar pattern holds true for the book values of assets with a median of 213 million and a mean of about 3.9 billion. Overall, the sample firm size characteristics are in line with existing studies. The average cash-to-total assets is approximately $13 \%$, which is similar to related studies.

The average ratios of Investment, operating income and ExternalFinance to total assets are $0.06,0.138$ and -0.005 , respectively. Corresponding figures for ratios to Capital are $0.11,0.3$ and 0.002 . Overall, these statistics are representative of those found in related studies.

The full sample summary statistics are not informative about the time series variation in key variables of interest to this study. In particular, there has been a significant increase in cash holdings over the sample period covered by this study. Comparing panels B and $\mathrm{C}$ in Table 1 we see that this feature of the evolution of cash holdings is reflected in the sample as well. This can be illustrated by e.g. the median Cash to Capital, which is $10 \%$ for observations belonging to the first half of the sample period while it has increased to an entire $21 \%$ for observations in the second half. Other firm characteristics do not display timer series patterns of similar economic importance. 


\subsection{Empirical Implementation}

The model is estimated using the Bajari et al. (2007) estimator, which avoids solving the model by applying a two-step approach motivated by key equilibrium conditions. Intuitively, the underlying idea of this method is to first estimate how actions are determined depending on states of the world, and how these states evolve according to past states and actions. This allows for estimation of firm value, and thus also the second step of the procedure which is finding the set of structural parameters that best rationalizes the observed equilibrium play. The latter is achieved by forming an objective function based on a revealed preference argument applied to observed versus suboptimal alternative policies. Thus, the estimator is based on the approach of Hotz et al. (1994) in the context of dynamic games. In short, the difference in estimated firm value stemming from suboptimal and observed policies depends on the parameters of the model and should not be positive. I.e. it is by definition better to choose actions that are optimal, and observed actions are assumed to be the optimal actions. The best set of parameters is then identified from minimizing a loss function build on this intuitive notion. The purpose of the model in this setting is therefore to explicitly define the state variables and their relation based on economic theory and similarly specify the objective of decision makers. In doing so, the model is also fundamental in identification in that it allows for estimation of value functions, and determines how the model parameters affects firm value given chosen policies, either optimal or suboptimal. The alternative of a full solution method as typically applied in the structural estimation literature in finance (see Hennessy and Whited, 2007, 2005) would be conceptually appealing, e.g. in terms of fully utilizing the structure of the model, and could be implemented with empirical policy functions representing firms' dynamic behavior, ${ }^{4}$ but multiplicity of equilibria and computational challenges make such

\footnotetext{
${ }^{4}$ See Bazdresch et al. (2199) for an analysis of this approach
} 
an approach for practical purposes infeasible given the theoretical framework used in this paper. The Bajari et al. (2007) estimator is well suited for handling the challenges of the model framework applied here. Contemporaneous estimators by Aguirregabiria and Mira (2007), Pakes et al. (2007), and Pesendorfer and Schmidt-Dengler (2008) are also based on similar ideas, but are challenging to apply here as the main actions of interest take the form of outcomes of continuous choice variables.

\subsubsection{First Stage: Policies, Transitions an Firm Value}

Equilibrium behavior is estimated from observed actions and states, assuming optimality of realized behavior as represented by functions of observed states. Optimal here refers to the best possible actions for a decision-making agent representing the influence of relevant stakeholders. For example, in a situation where a firm manager would like to make a choice very different from what equity holders would find optimal, the end result could be a compromise where the action take is not optimal for either party. In such situations, the emphasis here is on the actual actions taken, and the estimated parameters will be representative of the system that aggregates stakeholder preferences and transforms them into in corporate outcomes. The assumption of optimality of actions based on observed states introduces a potential concern in that unobserved serially correlated state variables could be relevant for observed actions, affecting the interpretation of the results as potentially capturing aspects other than strategic interaction. One such example is industry characteristics, which are likely to be influencing firms' cash holding decisions as recognized in early studies of cash holdings (for early empirical evidence see e.g. Chudson (1945), who emphasizes inter-industry variation in “... factors as the length and technical character of the production process, the durability of the product, the degree of vertical integration, and the amplitude of seasonal fluctuations."). However, several aspects of the empirical 
implementation here dampen such concerns. The main insights obtained from the analysis relies on the endogeneity present in the model framework, and the above mentioned concerns only affects the results to the extent that they are not captured by the model. Furthermore, the main specifications relate to effects of being different than peers. This is important, since identification of the model parameters stems from the behavior of firms over time and the extent to which firms move together more closely than what would be the case if peer effects were not present. Therefore, although industry effects seem relevant for the level of cash holdings, strategic interaction is likely a more important driving force for time variation in differences in cash holdings. Put differently, if some unobserved variable affects the cash holdings of all firms in an industry similarly, this will shift the distribution of cash holdings and make all firms have different levels of cash holdings. However, since the costs specification applied in this paper relates to the deviation from the median cash to capital ratio of peer firms, such an omitted variable will not invalidate identification since the deviation from peers is not influenced. Having shocks to such unobserved state variables could potentially affect the estimated peer effect parameters. I explicitly amend the identification strategy to ensure that this is not a concern. The data is sufficiently rich so that unobserved serially correlated state variables can be controlled for in policy function estimation and by allowing for parameter heterogeneity, although data availability somewhat constrains the degree to which one can allow for flexibility in first state estimates at the firm level, making approaches with agent-level policy functions such as e.g. Misra and Nair (2011) generally not feasible for large sets of firms. Lacking a suitable framework for endogenizing peer group structure, I therefore follow suggestions in Bajari et al. (2007) for first stage amendments aimed at overcoming concerns related to unobserved serially correlated state variables. I control for remaining confounding dynamics by constructing a state variable that captures unmodeled incentives to hold cash. In alternative approaches, I further estimate the model on data where variation to common determinants of cash hold- 
ings that are not included in the model is removed, as well as conduct an estimation using an alternative macro-proxy for the net cost of holding cash while imposing the assumption that peer effects are constant over time.

\section{Estimating Policy Functions}

Policy functions are estimated by regressions of the relevant actions on the common state vector with own profitability substituted in for expected own profitability since firms can observe their own profitability shocks. This is the description of how firms make decisions, and is thus a representation of optimal behavior as observed in the data, summarizing complex data by regression coefficients that allows for simulation of firm value. In order to allow for a flexible functional form, I use a quadratic polynomial specification which adds squared and interacted terms for all variables to the linear case. Depending on the specific state under consideration, the state space is potentially very large due to the presence of peer firms. For example, in a peer group having a total of 5 firms, in addition to own capital, cash, exogenous incentives to hold cash, profitability, any given firm's policies are also functions of cash, capital, exogenous incentives to hold cash and expected profitability for the other 4 firms, yielding a total of 20 state variables. In a peer group with 30 firms, the number of state variables would be 120. Therefore, additional assumptions are needed to facilitate estimation, given the length of the time series dimension for the unbalanced panel used in this study. In particular, I let peer firm variables be represented by their crosssectional medians, excluding the firms for which the observed action is used as a dependent variable in the estimation. Furthermore, due to potential size differences between firms and conventional scaling practice, for the purpose of policy function estimation I let capital enter as a scaling variable only, where capital refers to non-cash assets. In subsequent estimation of firm value, capital is used to recover policy levels. In order to allow for 
heterogeneity in estimated policy functions I use a finite mixture model. The finite mixture model is a special case of a random coefficients model in which the mixing density is a point-mass density. In particular, for a policy $y_{i, t}^{j}$ determined by observable data $x_{i, t}^{j}$ there are $K$ classes, each with separate coefficients $\beta_{k}$ in the quadratic polynomial specification with density $f\left(y_{i, t}^{j} ; x_{i, t}^{j}, \beta_{k}\right)$, having probability $\lambda_{k}$ jointly summing to one:

$$
\sum_{k=1}^{K} \lambda_{k}=1
$$

yielding the density

$$
f\left(y_{i, t}^{j} ; x_{i, t}^{j},\left\{\beta_{k}\right\}_{k=1}^{K},\left\{\lambda_{k}\right\}_{k=1}^{K}\right)=\sum_{k=1}^{K} \lambda_{k} f\left(y_{i, t}^{j} ; x_{i, t}^{j}, \beta_{k}\right)
$$

The class probabilities and coefficients with associated standard errors are estimated using maximum likelihood. In order to exploit heterogeneity along observable dimensions, I perform the estimation on sub-samples grouped by SIC codes meant to capture similarities in operations. For this purpose I rely on the Fama and French industry classification constructed to achieve 5 industry groups. ${ }^{5}$ The industries in the Fama and French 5industry classification are (1) "Consumer Durables, NonDurables, Wholesale, Retail, and Some Services (Laundries, Repair Shops)”, (2) “Manufacturing, Energy, and Utilities”, (3) "Business Equipment, Telephone and Television Transmission", (4) "Healthcare, Medical Equipment, and Drugs" and (5) "Other - Mines, Construction, Construction Materials, Transportation, Hotels, Business Services, Entertainment, Finance”. Among the first four Fama and French industries represented in my sample, I further collapse groups (1) and (4) together and group (2) and (3) together in order to obtain samples of sufficient size

\footnotetext{
${ }^{5}$ The data is available at http://mba.tuck.dartmouth.edu/pages/faculty/ken.french/data_library.html. See also Fama and French (1997).
} 
for estimation of policy functions. I refer to these two sets of firms as policy group I and policy group II, respectively.

The optimal choice of the number of latent classes is still an open problem. I follow a conventional procedure by applying the Bayesian information criterion to inform the choice of number of latent classes, resulting in 3 classes for the investment policy function and 4 classes for the external finance policy function for firms in policy group I (Fama Franch industries (1) and (4)), and 4 classes for both the investment and external finance policy functions for firms in policy group II.

\section{Estimating State Transitions}

Similarly to Matvos and Seru (2014), the dynamics of firm level productivity, measured by the return on assets, is estimated using linear splines with eight interior knots at the deciles of the productivity distribution. In order to ensure that each estimation is conducted using a sufficient number of observations, the estimations are conducted separately for subsamples defined by two digit SIC codes.

The transition of cash is estimated from a regression model on lagged state variables and choice variables, using a quadratic polynomial specification. Applying a Tobit model encompassing the non-negativity of cash holdings in the model is of little importance to the empirical implementation. The same holds true for the first stage estimation of the investment policy function. Depreciation is estimated as the average depreciation in the data, which is on average $9.2 \%$ for the full sample and similar to existing studies. In order to allow for heterogeneity in the depreciation rate, I estimate the depreciation rate on sub-samples defined by 2-digit SIC codes to the extent that these groups have a sufficient number of observations to support the estimation. This results in modest variation around the overall average depreciation rate of $9.2 \%$. 
The time series process of $\xi_{i, t}^{j}$ is estimated in two steps. First, the value of cash is estimated using an approach similar to Faulkender and Wang (2006) ${ }^{6}$. Specifically, the marginal value of cash is estimated as $\beta_{1}$ in the below regression, where $\beta_{1}$ is assumed to be normally distributed with mean values allowed to vary with peer group and time dummies:

$$
\begin{aligned}
& r_{i, t}^{j}-R_{i, t}^{B, j}=\beta_{0}^{j}+\beta_{i, 1}^{j} \frac{\Delta C_{i, t}^{j}}{M_{i, t-1}^{j}}+\beta_{2}^{j} \frac{\Delta E_{i, t}^{j}}{M_{i, t-1}^{j}}+\beta_{3}^{j} \frac{\Delta N A_{i, t}^{j}}{M_{i, t-1}^{j}}+\beta_{4}^{j} \frac{\Delta R D_{i, t}^{j}}{R D_{i, t-1}^{j}}+\beta_{5}^{j} \frac{\Delta I_{i, t}^{j}}{M_{i, t-1}^{j}} \\
& +\beta_{6}^{j} \frac{N F_{i, t}^{j}}{M_{i, t-1}^{j}}+\beta_{7}^{j} \frac{C_{i, t-1}^{j}}{M_{i, t-1}^{j}}+\beta_{8}^{j} \frac{L_{i, t-1}^{j}}{M_{i, t-1}^{j}}+\beta_{9}^{j} \frac{\Delta C_{i, t}^{j}}{M_{i, t-1}^{j}} \frac{L_{i, t-1}^{j}}{M_{i, t-1}^{j}}+\beta_{10}^{j} \frac{\Delta C_{i, t}^{j}}{M_{i, t-1}^{j}} \frac{L_{i, t-1}^{j}}{M_{i, t-1}^{j}}+\epsilon_{i, t}^{j}
\end{aligned}
$$

i.e. $\beta_{i, 1}^{j}=\sum_{j_{3}=1}^{J_{3}} \mathcal{I}_{j_{3}}+\sum_{y=1}^{Y} \mathcal{I}_{y}+\epsilon_{\beta_{i, 1}^{j}, t}^{j}$, where $J_{3}$ is the number of peer groups at the three digit SIC level, $Y$ is the number of years, $\mathcal{I}_{j}$ is an indicator for membership in peer group $j, \mathcal{I}_{y}$ is an indicator variable for an observation belonging to year $y, r_{i, t}^{j}$ is the return of firm $i$ in peer group $j$ during period $t, R_{i, t}^{B, j}$ is the corresponding benchmark return, $M$ is market values, $C$ is cash, $L$ is leverage, $E$ is profits, $N A$ is non-cash assets, $R D$ is $R \& D$ expenses, $I$ is interest expense, Debt is debt, $N F$ is external financing net of dividends. The differences in values of cash are allowed to vary at the three digit SIC code level, which is necessary in order to identify all parameters of the model. It is also reasonable to assume that the shocks to the value of holding cash are relatively consistent at this level of abstraction in terms of industry definition.

Second, hedonic prices of other state variables are estimated using the method of Bajari et al. (2012). The starting point is a panel of prices in the form of individual level posterior estimates of marginal values of cash and characteristics in the form of other state vari-

\footnotetext{
${ }^{6}$ See e.g. Denis and Sibilkov (2010); Dittmar and Mahrt-Smith (2007) for studies examining the value of cash with the same methods.
} 
ables. The objective is to estimate the time series model of the error term in the following regressions:

$$
p_{i, t}^{j}=\alpha_{0}^{j}+\alpha_{1}^{j^{\prime}} x_{i, t}^{j}+\xi_{i, t}^{j}
$$

where $x$ is a vector consisting of the state variables of the model, and $p_{i, t}^{j}$ is the value of cash estimated as $\beta_{i, 1}^{j}$ from the above regression specification. Recall that $\xi_{i, t}^{j}$ is unobserved characteristics driving cash holdings, assumed to follow a first-order Markov process:

$$
\xi_{i, t+1}^{j}=\mu_{t, t+1}^{j} \xi_{i, t}^{j}+\eta_{i, t, t+1}^{j}
$$

$\eta_{i, t, t+1}^{j}$ is assumed independent of information at time $t$, stemming from efficient markets and lack of predictability. Bajari et al. (2012) show that $\left\{\alpha_{0}^{j}, \alpha_{1}^{j}, \mu_{t, t+1}^{j}\right\}$ can be estimated using a two-stage nonlinear least squares estimator where the first stage is regression current characteristics on lagged characteristics and prices. $\xi_{i, t}^{j}$ can then be estimated as residuals in the hedonic pricing equation, and will be used as a state variable for unobserved factors driving cash holdings, where simulation is facilitated by the time series evolution of the unobserved characteristics.

I implement the above estimator using a control function approach (Heckman and Robb, 1985; Imbens and Newey, 2009), following a recent application in finance by Matvos (2013). It follows from the above that:

$$
\begin{aligned}
p_{i, t}^{j} & =\alpha_{0}^{j}+\alpha_{1}^{j^{\prime}} x_{i, t-1}^{j}+\mu_{t-1, t}^{j} \xi_{i, t-1}^{j}+\eta_{i, t-1, t}^{j} \\
& =\alpha_{0}^{j}+\alpha_{1}^{j^{\prime}} x_{i, t-1}^{j}+\mu_{t-1, t}^{j}\left(p_{i, t-1}^{j}-\alpha_{0}^{j}-\alpha_{1}^{j^{\prime}} x_{i, t-1}^{j}\right)+\eta_{i, t-1, t}^{j}
\end{aligned}
$$

The identification threat to the above is that $\eta_{i, t, t+1}^{j}$ is potentially correlated with the state variables of the model. However, the value of cash is informative about the incentives to use cash from unobserved characteristics, i.e. other factors than state variables of the 
model, and can be used to form an consistent estimator as proposed by Bajari et al. (2012). First, obtain the innovations $\widehat{v}_{i, t}^{j}$ to the state variables from a linear regression (the function $G()$ is assumed linear) having lagged state variables and values of cash as explanatory variables.

$$
x_{i, t+1}^{j}=G\left(x_{i, t}^{j}, p_{i, t}^{j}\right)+v_{i, t}^{j}
$$

Furthermore, allow these innovations to be correlated with the innovations to unobserved characteristics through the following linear model with coefficients $H$ :

$$
\eta_{i, t-1, t}^{j}=H^{\prime} v_{i, t}^{j}+\epsilon_{\eta_{i, t-1, t}^{j}}
$$

Substituting the above into equation 3.6 we arrive at

$$
p_{i, t}^{j}=\alpha_{0}^{j}+\alpha_{1}^{j^{\prime}} x_{i, t-1}^{j}+\mu_{t-1, t}^{j}\left(p_{i, t-1}^{j}-\alpha_{0}^{j}-\alpha_{1}^{j^{\prime}} x_{i, t-1}^{j}\right)+H^{\prime} v_{i, t}^{j}+\epsilon_{\eta_{i, t-1, t}^{j}}
$$

Due to market rationality, $\epsilon_{\eta_{i, t-1, t}^{j}}$ will be orthogonal to model state variables, and allows for a GMM estimator defined by the following moment conditions:

$$
\begin{array}{r}
E\left[p_{i, t}^{j}-\left(\alpha_{0}^{j}+\alpha_{1}^{j^{\prime}} x_{i, t}^{j}+\mu_{t-1, t}^{j}\left(p_{i, t-1}^{j}-\alpha_{0}^{j}-\alpha_{1}^{j^{\prime}} x_{i, t-1}^{j}\right)\right.\right. \\
\left.\left.+H^{\prime} \widehat{v}_{i, t}^{j}+\epsilon_{\eta_{i, t-1, t}^{j}}\right) \mid x_{i, t}^{j}, x_{i, t-1}^{j}, p_{i, t-1}^{j}, \widehat{v}_{i, t}^{j}\right]=0
\end{array}
$$

where the conditioning information are used as instruments. In the empirical implementation I also impose that $\mu_{t-1, t}^{j}=\mu^{j}$, i.e. the time series model of the unobserved characteristics driving cash holding decisions is constant within peer groups. The estimates are further obtained at the three digit SIC code level to ensure a sufficient amount of observations to perform the estimation. In the event that the estimation cannot be performed at the three digit SIC code level, the estimation is done at the two digit SIC code 
level.

\section{Simulating Firm Value}

Equipped with estimates for how actions are chosen and states evolve, firm value can be estimated for any given starting state. Recall from equation 2.12 that a firm's value function is given by

$$
\begin{aligned}
& V_{i}^{j}\left(\boldsymbol{s}^{j} ; z_{i}^{j} ; \xi_{i}^{j} ; \boldsymbol{\sigma}^{j} ; \theta\right)= \\
& E\left[\sum_{t=0}^{\infty} \beta^{t} u_{i, t}^{j}\left(\boldsymbol{\sigma}^{j}\left(\boldsymbol{s}_{\boldsymbol{t}}, \boldsymbol{\epsilon}_{\boldsymbol{z}, \boldsymbol{t}}^{j}\right), \boldsymbol{s}_{\boldsymbol{t}}^{j}, \epsilon_{z, i, t}^{j} ; \theta\right) \mid \boldsymbol{s}_{\mathbf{0}}^{j}=\boldsymbol{s}^{j} ; z_{i, 0}^{j}=z_{i}^{j} ; \xi_{i, 0}^{j}=\xi_{i}^{j} ; \theta\right]
\end{aligned}
$$

Given the estimated policy functions and state transitions as described above, the value function of firm $i$, state $s^{j}$ and strategy profile $\boldsymbol{\sigma}^{j}$ can be estimated as follows:

1. Draw the initial state $s_{0}^{j}=s^{j}$.

2. Draw shocks to profitability, $\xi_{i}^{j}$ and the common shock to external finance.

3. Calculate actions $a_{i}^{j}\left(s_{t}\right)=\sigma_{i}^{j}\left(s_{t}\right)$.

4. Calculate profits and firm utility.

5. Draw the new state $s_{t+1}^{j}$ using the estimated transition probabilities.

6. Repeat the above steps for $\mathrm{T}$ periods.

7. Approximate the continuation value at time $T$ by the capital stock of the firm.

8. Calculate present discounted value. 
The above algorithm is repeated $N_{s}$ times in order to provide an estimate of the value function. In the empirical implementation I set $N_{s}=500, T=50$ and $\beta=0.95$, ensuring that assumptions about the continuation value of the firm in the final period is of little significance. Note that the timing convention underlying $T$ corresponds to that of the frequency of observations in the data, i.e. for a final point of time $T=50$ there will be 50 years of data for each simulation. Firms are not allowed to undertake any action more extreme than that collectively observed in the data.

A computationally convenient feature of the model is the linearity of the utility function. With the above definition of the utility function, we can define $\Psi_{i, t}^{j}\left(s_{t}^{j} ; z_{i, t}^{j} ; \xi_{i, t}^{j} ; \xi_{i, t}^{j} ; \sigma_{i}^{j}, \boldsymbol{\sigma}_{-i}^{j}\right)$ as a vector with cash flow net of investment as the first element and each of the individual state variable factors of the cost components as further elements. The utility function can then be written as $\Psi_{i, t}^{j}\left(\boldsymbol{s}_{\boldsymbol{t}} ; \boldsymbol{\sigma}^{j} ; z_{i, t}^{j} ; \xi_{i, t}^{j}\right) \times[1, \theta]^{\prime}$ and thus the value function becomes

$$
V_{i}^{j}\left(\boldsymbol{s}^{j} ; \boldsymbol{\sigma}^{j} ; z_{i}^{j} ; \xi_{i}^{j} ; \theta\right)=\Psi_{i}^{j}\left(\boldsymbol{s}^{j} ; z_{i}^{j} ; \xi_{i, t}^{j} ; \boldsymbol{\sigma}^{j}\right) \times[1, \theta]^{\prime}
$$

where

$$
\Psi_{i}^{j}\left(\boldsymbol{s}^{j} ; z_{i}^{j} ; \xi_{i, t}^{j} ; \boldsymbol{\sigma}^{j}\right)=E\left[\sum_{t=0}^{\infty} \beta^{t} \Psi_{i, t}^{j}\left(\boldsymbol{s}_{\boldsymbol{t}} ; \boldsymbol{\sigma}^{j}\right) \mid \boldsymbol{s}_{\mathbf{0}}^{j}=\boldsymbol{s}^{j} ; z_{i, 0}^{j}=z_{i}^{j} ; \xi_{i, 0}^{j}=\xi_{i}^{j}\right]
$$

This significantly reduces computation time because $\Psi_{i}^{j}\left(\boldsymbol{s}^{j} ; z_{i}^{j} ; \xi_{i}^{j} ; \boldsymbol{\sigma}^{j}\right)$ can be simulated independently of $\theta$, avoiding the need to repeat the simulation for every amendment of $\theta$ in an optimization procedure. 


\subsubsection{Second Stage: Identifying Structural Parameters}

The second stage of the Bajari et al. (2007) procedure uses the characterizing restrictions on firms' evaluation of observed versus rejected actions of the Markov Perfect Equilibrium to estimate the structural parameters $\theta$. Recall that from the definition of Markov Perfect Equilibrium, firm $i$ should not be able to profitably deviate to some other policy $\sigma_{i}^{j^{\prime}}$ given the beliefs about other players' policies. It should therefore be the case that for all $i, s^{j}, z_{i}^{j}$, $\xi_{i, t}^{j}$ and feasible $\sigma_{i}^{j^{\prime}}$ given the model:

$$
V_{i}\left(\boldsymbol{s}^{j} ; z_{i}^{j} ; \xi_{i}^{j} ; \sigma_{i}^{j}, \boldsymbol{\sigma}_{-i}^{j} ; \theta\right) \geq V_{i}\left(\boldsymbol{s}^{j} ; z_{i}^{j} ; \xi_{i}^{j} ; \sigma_{i}^{j^{\prime}}, \boldsymbol{\sigma}_{-i}^{j} ; \theta\right)
$$

The implementation relies on the assumption that a unique equilibrium is played in the data at a level of abstraction equal to that of policy function estimation, correspondingly allowing for heterogeneity in equilibrium strategies in some of the results. Importantly, this does not imply uniqueness of equilibrium in the model, and thus sidesteps challenging theoretical refinements of the applied equilibrium concepts through cousin assumptions about the observed behavior in the data.

The basic idea in establishing an estimator of $\theta$ from the above framework is to impose a penalty when $V_{i}\left(\boldsymbol{s}^{j} ; z_{i}^{j} ; \xi_{i}^{j} ; \sigma_{i}^{j}, \boldsymbol{\sigma}_{-i}^{j} ; \theta\right) \geq V_{i}\left(\boldsymbol{s}^{j} ; z_{i}^{j} ; \xi_{i}^{j} ; \sigma_{i}^{j^{\prime}}, \boldsymbol{\sigma}_{-i}^{j} ; \theta\right)$ does not hold, and then search over $\theta$ to find the true $\theta_{0}$ that minimizes this penalty. Bajari et al. (2007) propose to estimate $\theta$ by minimizing the following function with respect to $\theta$ :

$$
\int \mathcal{L}(\min \{g(x ; \theta), 0\}) d H(x)
$$

where $\mathrm{H}$ is a distribution over the set of inequalities $g(x ; \theta) \geq 0, \mathcal{L}(\min \{g(x ; \theta), 0\})=$ $(\min \{g(x ; \theta), 0\})^{2}$ and 


$$
g(x ; \theta)=V_{i}\left(\boldsymbol{s}^{j} ; z_{i}^{j} ; \xi_{i}^{j} ; \sigma_{i}^{j}, \boldsymbol{\sigma}_{-i}^{j} ; \theta\right)-V_{i}\left(\boldsymbol{s}^{j} ; z_{i}^{j} ; \xi_{i}^{j} ; \sigma_{i}^{j^{\prime}}, \boldsymbol{\sigma}_{-i}^{j} ; \theta\right)
$$

For the loss function $\mathcal{L}(\min \{g(x ; \theta), 0\})$ I use the $L_{1}$ norm instead of the Euclidian distance proposed in Bajari et al. (2007) in order to dampen the effects of outliers. From the linearity of the profit function as shown in equation 3.12, the computational gains are clear from the specification of $g(x ; \theta)$ since the components $\Psi_{i}^{j}\left(\boldsymbol{s}^{j} ; z_{i}^{j} ; \xi_{i}^{j} ; \boldsymbol{\sigma}^{j} ; \theta\right)$ for observed and alternative policies can be estimated independently of the common $\theta$.

I apply the sample counterpart of equation 3.15 in estimating the model parameters, and use peer group-year combinations as initial states, resulting in a total of 3146 initial states for the 109 peer groups for the 1972 to 2015 time period. For every initial state, 150 deviating policies for both investment and external finance are considered. The deviating firms are chosen randomly using a uniform distribution. I use a variant of the differential evolution algorithm by Storn and Price (1997), followed by a Nelder-Mead algorithm, to find the set of parameter estimates, and estimate standard errors by a bootstrapping procedure with 100 redrawn samples of the second stage. The latter does not take into account simulation error, and results in estimates of standard errors that are conservative in value. 


\section{Estimation Results}

In this section I present the main results quantifying peer effects in corporate cash holdings. The main results containing the structural parameters are presented in Section 4.2, which is preceded by an analysis of the estimated policy functions and laws of motion in Section 4.1. In Section 4.3 I present results where the peer effects parameters are allowed to vary with certain characteristics, while Section 4.4 and Section 4.5 contain analyses of the sensitivity of the estimated peer effects parameters to the estimated cost of investment and external finance, respectively. In Section 4.6 I provide results from alternative identification strategies. An interpretation of the quantitative effect of peer effects on firm behavior is found in Section 4.7.

\subsection{Policy Functions and State Transitions}

The policy and state transition functions are the basic representations of firm behavior and environment evolution as observed in the data, making possible simulation of firm behavior and thus also identification of the structural parameters of the model though the Bajari et al. (2007) estimator. In the identification strategy I also use the estimated values 
of cash to calculate a state variable for the incentives to hold cash not captured by the model directly. This state variable enters the policy functions for investment and external finance, and I therefore begin with a discussion of the properties of this state variable and its basic components.

Figure 1 shows how the estimated marginal values of cash evolve over time using a polynomial smoothing estimator. Consistent with the well documented increase in cash holdings over the sample period, there is a general increase in the marginal value of cash throughout the sample period. This pattern is similar to Bates et al. (2011), who document a general increase in the value of cash holdings during the 1980-2009 period, and investigate the determinants of this time trend as well as the time variation in their importance in explaining the changes in the value of cash. Keefe and Kieschnick (2013) analyze the time variation in the value of cash holdings, emphasizing the role of macroeconomic conditions.

Figure 2 shows the AR(1) coefficients $\mu_{t, t+1}^{j}$ that governs the dynamics of the cash incentive shocks $\xi_{i, t+1}^{j}$ through the process $\xi_{i, t+1}^{j}=\mu_{t, t+1}^{j} \xi_{i, t}^{j}+\eta_{i, t, t+1}^{j}$. The coefficients are unrestricted in the regressions, but all coefficients are strictly less than one. The coefficients display an overweight towards relatively persistent shock processes, consistent with intuitive conjectures about the nature of incentives to hold cash.

Finally, in Table 2 I show results from regressions of the AR(1) coefficients $\mu_{t, t+1}^{j}$ of the cash incentive shocks on peer group characteristics. Since the AR(1) coefficients are constant within each group, I use group characteristics calculated as averages or standard deviations over time and firms within each group as explanatory variables in the regressions. The groups here are defined by 3-digit SIC codes, and differ from the main definition of peer groups used in the paper due to data requirements for estimation of the $\operatorname{AR}(1)$ coefficients, as explained in Section 3.2.1. The purpose of the regressions is to show how 
the estimated persistence parameters relate to peer group characteristics. Among model state variables, I find that the persistence $\mu_{t, t+1}^{j}$ of the cash incentive shocks is significantly positively associated with standard deviation of unobserved cash shocks. Other firm characteristics show little relation to the estimated coefficients, but the estimated regressions provide some support for the variables $R \& D$ and Fluidity being significantly negatively related to the $\operatorname{AR}(1)$ coefficients $\mu_{t, t+1}^{j}$ of the cash incentive shocks. I.e. firms facing higher product market threats or engaging in more $R \& D$ activity, have cash incentive shocks that are relatively less persistent than those of firms not subject to the same level of threat from competitors or not relying in $R \& D$ to the same extent in their business model.

Policies for investment and external finance are estimated based on the other state variables of the model. In figures 3 and 4 the policy functions for investment and external finance are displayed through plots of their estimated values for different values of the other states variables. Each graph show the variation in the policy under study as a function of one other state variable, with other independent variables of the policy functions held constant at their sample average levels. The estimated policies are reduced-form description of firm behavior, and the second stage of the estimation procedure uses the model framework to identify the structural parameters based on these descriptions of firm behavior.

Comparing the investment policy functions for policy groups I and II in figures, we see that the latent classes are useful in capturing heterogeneity withing groups, while the partition based on the Fama and French industry classifications also captures heterogeneity between industries. The same overall picture also holds for the external financing policy functions in Figure 4.

From the policy functions we see how investment and external finance are chosen depending on e.g. the cash holding of peer firms. Key to the analysis here is the notion that firms hold cash partly because of the way other firms choose their cash holdings, and thus 
we would expect to see an effect of peer firm cash holdings on cash holdings for any given firm under study. From the policy functions we can see that there is indeed such an effect by considering how investment and external finance is chosen based on the cash holdings of peer firms. However, the exact magnitude of the effect is not immediately obvious from the policy functions, and I therefore perform an analysis of the policy function targeted at understanding the relation between the cash holdings of a firm and its peers. In particular I show impulse-response functions of a shock to peer cash holdings in Figure 5.

In Figure 5 I have chosen a peer group-year with four firms that I let be equipped with average profitability. Base on the initial state as shown in the above table, I find the steady state cash levels for all firms, and compare this to a counterfactual scenario where I exogenously increase the cash holdings of firms three and four, as compared to the steady state level. The idea is to see the effect of a shock to peer cash holdings as measured by the median of the peer group, which is why I choose to let two out of four firms have increased cash holdings. From Panel A of Figure 5, where I exogenously double the cash holdings of firms three and four, we see that there is a gradual increase in cash holdings of firms one and two, peaking at years six and seven with levels of 0.72 and 0.74 for firms one and two, respectively. Even though all firms eventually revert back to their initial steady state cash holdings, the impact is quite strong even after 20 years. Overall, we see that the estimated policy functions imply significant interaction effects among peer firm cash holdings, and the main analysis to be presented provides an interpretation of what this correlation between cash holding decisions mean from the perspective of decision makers in terms of their utility functions. Note that this analysis shows a large relative effect in the increase of peer cash holdings. In Panels B and C I conduct similar exercises for exogenous increases in the cash holdings of firms three and four that are of smaller magnitudes, and document a similar relative pattern. Thus the relative effect of peer firm cash holdings 
changes is not driven by the particular level of the exogenous change considered.

However, before presenting the main results, I further provide information about the policy functions from the perspective of their predictive properties. In Table 3 I provide summary statistics of expected firm characteristics generated by the estimated policy and state transition functions, using the observed data as initial values.

The expected future firm characteristics have intuitive properties, such as for example decreasing cross-sectional heterogeneity over time. Profitability and investment converge in a fairly short amount of time, while cash holdings and external finance requires quite a long time to converge.

\subsection{Main Estimation Results from Model with Peer Group Shocks to Cash Holding Incentives}

In this section I present results from the estimation where I allow for shocks to cash holding incentives, captured by the state variable $\xi_{i, t}^{j}$. Summarizing the construction of $\xi_{i, t}^{j}$, I obtain firm level marginal values of cash using an event study approach in the spirit of Faulkender and Wang (2006). I estimate the variation in these marginal values that can be explained by other model state variables, leaving a measure of incentives to hold cash not otherwise captured by the model. I further estimate the time series properties of this state variable assuming a common structure within peer groups.

\section{Estimation Results}

Table 4 contains estimation results for the baseline estimation conducted on the full sample. Of particular interest to this study are the parameters determining the effect of being 
different in terms of the ratio of cash holdings to capital. The estimated cost of being being below the peer group median in terms of cash holdings is approximately $\$ 812,000$ for every incremental percentage point, with a corresponding figure of $\$ 992,000$ for being above the peer group average. For a firm equipped with average characteristics, the peer cost of cash associated with every percentage point decrease in cash holdings relatively to its peers corresponds to approximately $0.16 \%$ of operating income and $0.04 \%$ of capital. In the extreme situation of holding no cash, the corresponding cost for a firm facing otherwise median characteristics would be almost $1.4 \%$ of the firm's capital. At median characteristics, every percentage point a firm falls below the peer group median is evaluated as a $3.2 \%$ reduction in operating income or a $0.7 \%$ reduction in capital.

From the above results we can see that firms put significant weight on their peers' policies in deciding on how much cash to hold. An additional dollar of cash is costly to hold if in excess of peers, but is evaluated as having a cost if the company is below the peer group. The interaction with $\xi$ is of relatively minor importance.

However, there is likely heterogeneity in the cost the firms experience by being different than their peers, and the USD 812.600 cost is probably not accurate for very small or very large firms. Therefore, I amend the specification to allow this cost to be a fraction of operating income or capital in order to better capture the effects of firms size. These results are shown in Table 5. In Panel A I let the coefficient be a fraction of operating income, and find that $\gamma_{p, 2}^{j}=1.003$. This means that if a firm has no cash and the peers have a median cash-to-capital ratio of 1 , the firm experiences a disutility of this situation that is valued equal to a loss of the operating income for that period. In other words, for every percentage point a firm falls behind the peer group median cash holdings, there is a disutility equal to 1 percent of operating income. The corresponding cost for being above the peer group median cash holding is $0.87 \%$. 
From Panel B of Table 5 we can see that the specification is robust to the scaling variable. The cost of being above the peer group median cash holdings is $0.38 \%$ of capital for every percentage point a firm is above the cash holding of peers, with a corresponding cost of $0.23 \%$ for being below. The overall message is that firms put a significant emphasis on their peer firms when deciding on how much to save and how much to invest.

Obtaining external finance is associated with a marginal cost of $7.9 \%$, which is reasonably in line with other studies, see Nikolov and Whited (2014). Finally, at mean values the investment adjustment costs constitute approximately the investment amount. This relatively large adjustment cost justifies observed investment patterns given the assumed constant returns to scale production function. Using estimated parameters from Cooper and Haltiwanger (2006), in particular a fixed investment adjustment cost of 3.9\% of capital and a convex adjustment cost parameter of 0.049 , the investment adjustment costs would be $44 \%$ of the investment amount when evaluated at median values and $35 \%$ when evaluated at mean values. The most significant driver of the relatively large investment adjustment cost is the estimated fixed cost of investment.

\subsection{Parameter Heterogeneity}

It is possible to learn more about the nature of peer firm costs of cash through estimations that capture parameter heterogeneity. With learning and competitive considerations as key motivating drivers of peer effects, proxies capturing these aspects of firms and industries are natural candidates to base heterogeneity on. If competitive threats are a major source of the peer cost of cash holdings, proxies for different aspects of product market competition should be associated with higher estimated peer costs of cash holdings when suggesting more intensive threats in the product market. The level of R\&D activity is 
likely to have similar effects if cash is held to purchase e.g. patents or other firms for competitive purposes. Finally, using proxies for the information environment of firms is analogously motivated by the potential for learning to influence peer costs of corporate actions.

In table 6 I show estimates of the peer parameters $\gamma_{p, 1}^{j}$ and $\gamma_{p, 2}^{j}$ for sub-samples formed based on the respective characteristics. For each characteristics chosen I split the sample based on whether any given observation is above the sample median based on firms insample average values.

They key findings displayed in table 6 show mostly intuitive patterns. The behavior of firms that have lower average $R \& D$ costs relative to their size reveal a stronger tendency for mimicking behavior in cash holdings, consistent with the notion that these firms have lower ability to differentiate themselves from competitors through product choice. This idea is based on the framework of Sutton (1991). Hoberg and Phillips (2016) and Ellickson (2007) test this theory in the context of Compustat firms and the supermarket industry, respectively. Finally, I use the probability of informed trading (PIN) measure of Brown and Hillegeist (2007) to investigate the effects of information asymmetry. PIN uses trading data to estimate the probability that trades are made by privately informed investors, and is high when information asymmetry is high. I find that peer effects in cash holdings are stronger when information asymmetry is high. In particular, the cost parameter of the sample with low PIN is 0.94 while that of the high PIN group is 1.16 . Finally, since the model otherwise do not explicitly incorporate taxes, I investigate the robustness of the results to heterogeneity in firm marginal tax rates. I find that the results are robust to firms' tax situations, though the peer parameters are economically more significant when tax rates are high. 


\subsection{Sensitivity to the Cost of Investment}

In this section I investigate the extent to which the estimated peer effect parameters depend on the level of the estimated cost of investment. In particular, I set the investment cost parameter equal to different pre-specified levels before running the optimization routine for other variables, treating this parameter value as known. This achieves an understanding of the sensitivity of the inference made to the value of the parameter capturing the cost of investment, i.e. how important the exact level of estimated investment cost is.

From table 7 we can see that the overall importance of peer effects in cash holdings are robust to the estimated value of the cost of investment. The changes to the investment cost parameters considered are quite large, and subsequently the other parameters of the model are also affected. However, for any pre-specified level considered, there are large peer effects in corporate cash holdings. Furthermore, the inference is also robust to exclusion of the quadratic cost component. Note that the difference in the peer effect parameters $\gamma_{p, 1}^{j}$ and $\gamma_{p, 2}^{j}$ is also consistently large.

\subsection{Sensitivity to the Cost of External Finance}

Since investment, cash holdings and external finance are closely linked by accounting identities, I also explore the sensitivity of the estimated peer effect parameters with respect to the cost of obtaining external finance, similar to the analogous analysis in the previous section focusing on investment costs.

In Panel A of Table 8 I estimate the model allowing for peer effects in external finance, and find that the magnitude of peer effects in cash holdings increase. In Panel B I change the cost of raising external finance and show the resulting peer effect parameters of cash. 
For the changes in the cost of external finance considered, there are only relatively minor associated changes in the cash peer parameters. Overall, these findings consistently document a substantial role for inter-firm relations in firm cash holding policies.

\subsection{Results from Alternative Identification Strategies}

The previous analysis suggest that there is a significant emphasis on peer cash holdings in determining optimal cash policies. The analysis so far relies on an approach that uses variation in firm value attributable to changes in cash that cannot be explained by model state variables to control for confounding factors influencing firm actions. In this section, I amend the estimation strategy to provide further support the robustness of the results by tackling endogeneity concerns from different angels.

\subsubsection{Peer Effects after Purging Out Common Cross-Sectional Deter- minants of Cash Holdings}

The empirical strategy so far has been to incorporate potential confounding factors through an additional state variable, the supplemental approach here is to remove variation from the data that is driven by factors outside the model. The idea is to estimate regressions of the state variables of the model on common determinants of cash holdings, and then re-estimate the model on the data that cannot be explained by these variables. One issue here is that the presence of peer effects might also make the estimated coefficients of these initial regressions inconsistent. In order to overcome this issue, I use lagged instruments to estimate this first set of regressions.

The first step of the amendment consists of removing the variation in state variables 
that is driven by other determinants of cash holdings. Specifically, for any state variable $y_{i, t}^{j}$ I estimate the following regression:

$$
y_{i, t}^{j}=X_{i, t}^{j^{\prime}} \beta+\epsilon_{i, t}^{j}
$$

where $X_{i, t}^{j^{\prime}}$ is a set of determinants known to affect cash holdings and $\beta$ are the associated coefficients. The set $X_{i, t}^{j^{\prime}}$ includes the variables $M B, R \& D$, Tangibility, Acquisitions, CreditRating. MB is the market-to-book ratio calculated as ((Total Assets-(Total AssetsTotal Liabilities +Deferred Taxes and Investment Tax Credit)+(Market Value of Equity))/Total Assets.), $R \& D$ is research and development expenses scaled by total assets (missing values for research and development have been replaced by zero), Tangibility is net to gross property, plant and equiptment, Acquisitions is acquisitions to total assets and CreditRating is a dummy variable for the presence of a Standard \& Poor's credit rating. The estimation is based on lagged instruments to overcome endogeneity issues, and is implemented using a control function approach. The model is then re-estimated using the part of the state variables $y_{i, t}^{j}$ that is not explained by $X_{i, t}^{j^{\prime}}$.

Table 9 contains the estimation results from the above empirical approach. Comparing to the previous results, we see that the overall role of peer effects in corporate cash holdings remains significant and robust to this alternative approach.

\subsubsection{Identification from Time-Invariant Peer Effects}

I consistently find significant peer effects both in an approach that incorporates potential confounding factors through an additional state variable and when variation in the data that is driven by factors outside the model is removed. The latter relies on an instrumental variables approach that require low variation in peer effects over time. However, if we 
assume that peer effects are constant over time, there are further options for identification. In particular, I will let other costs of holding cash be determined by an exogenous state variable known to drive the cost of holding cash, allowing for identification of peer effects through incorporating this state variable in the model. Compared to the above approach constructing a state variable that is based on joint variation in cash holdings and stock prices, which does not require peer effects to be constant over time, the idea here is to lever the assumtion that peer effects are constant, allowing for identification from a proxy state variable driving cash holdings though not necessarily measuring the value of cash.

I use the TED spread as an exogenous shock to the cost of holding cash. The TED spread is defined as the difference between the three-month LIBOR and the three-month T-bill interest rates, and is a common indicator of credit market distress and therefore also relevant for the incentives to hold cash. I denote the Ted-spread by $\xi_{i, t}^{T E D}$, and include it as an exogenous state variable following a first-order Markov process.

Table 10 contains the estimation results from the above empirical approach centered around the assumption that peer effects are constant over time. Focusing on the main variables of interest, we have that $\gamma_{p, 2}^{j}=0.51$. Compared to the baseline estimation displayed in Table 5 the effect is dampened, but still economically very significant; firms behave as if for every percentage point a firm falls behind the peer group median cash holdings, there is an evaluated cost equal to approximately 0.5 percent of operating income. In order to further evaluate the implications this finding has for firm behavior, Section 4.7 continues with an evaluation of how firm behavior would change in a model of cash holdings if the peer effect cost parameters from Table 10 above were introduced. 


\subsection{Interpreting the Magnitude of Peer Effects}

So far the main specifications relate the peer effect costs parameters to quantities like operating income and capital. To further investigate the importance of peer effects, this section will be devoted to the impact of peer effects on firm performance. Due to the complexity of the model, I am not able to do counterfactual experiments where I solve the model for different cost parameters characterizing peer effects to see the impact it has on firm behavior. As an alternative, I will instead use a different model of corporate cash holdings to evaluate the importance of peer effects. In particular, I will compare firm behavior from such a model to that of an amended model where I introduce the peer effect cost parameters I have estimated.

The basic model I apply is similar to the discrete time investment model with cash holdings in Strebulaev and Whited (2012), which the model used in the above analysis is also based on. Firms receive cash flows $z_{i, t} k_{i, t}^{\theta}$ that are taxed at a rate $\tau$. Profitability $z_{i, t}$ follows an $\operatorname{AR}(1)$ in logs with autocorrelation-coefficient $\rho$ and error standard deviation $\sigma_{\rho}$. External finance is raised at a cost $\phi_{e}$ and can be distributed freely. Investment, positive or negative, can be made with adjustment costs equal to $\phi_{I} \frac{I^{2}}{k}$. In this model cash is costly due to taxes, but has value because external finance is costly.

I solve the model numerically, and simulate firm behavior, using a tax rate of $20 \%$, an autocorrelation coefficient of $\log$ profitability of 0.7 with an error standard deviation of 0.3 , a quadratic investment adjustment cost of $0.05, \theta$ is 0.7 , depreciation of $15 \%$, and a risk-free interest rate of 0.04 . In order to introduce heterogeneity in the desire to hold cash, I let firms be equipped with different costs of raising external equity. One could similarly introduce other costs of cash, or change other aspects of firms' environments in order to achieve the same. For the purpose of illustrating the importance of peer effects, I only focus on introducing heterogeneity in one dimension without extending the model 
further. In order to study the importance of peer effects, I also amend this setup with the peer effect cost parameters as found in Table 10 above. This introduces severe computational challenges, both due to multiplicity of equilibria and a very big state space. For the purpose of solving the model with peer effects, I apply an amended version of the oblivious equilibrium concept of Weintraub et al. (2008) and Weintraub et al. (2010). ${ }^{1}$ The basic idea is to let firms optimize as if ignorant about the states of other firms except for industry long-run averages, making implementation computationally less demanding. In particular, I let firms achieve utility from deviating from the industry median calculated over time and firms (and not the median per period as in the main specification above). This allows for a guess-and-verify approach where I exogenously impose a median ratio of cash to capital, and then search for the assumed median cash ratio that is as close as possible to the corresponding statistic from simulations based on the model solution given the assumed cash ratio. The results are displayed in Table 11. Firms are identified by their cost of external finance parameters as found in Table 11 below, where Panel A refers to the model without peer effects and Panel B to the model with peer effects.

From Panel A of Table 11 we see that the heterogeneity in costs of external finance generates differences in cash holdings that are increasing in the cost of external finance. The overall median cash holdings is 0.075 and the average is 0.249. In Panel B I show simulated statistics from the models with peer effects. With the cost parameters from the estimation displayed in Table 10, I find that the new equilibrium median cash holdings is 0.1 , and that all firms reach this as their own median except the firm with the highest cost of external finance, which also has a median close to the overall value. This result stem from the fact that the only difference between firms is the cost of external finance, and introducing stronger heterogeneity might moderate this solution. However, there is

\footnotetext{
${ }^{1}$ See also Weintraub et al. (2006)
} 
still significant heterogeneity over time depending on the realized profitability shock of each firm. The average levels of cash are also greatly reduced, consistent with the notion that firms shift their cash holding distributions to avoid deviating from other firms. Since the model parameters are not chosen to match the data used in this study, the differences in cash holdings observed with and without peer effects do not correspond to the difference we would see if real-world firms were to operate in isolation, but rather illustrates the quantitative importance of peer effects in light of common models used in corporate finance research. 


\section{Conclusion}

The tradeoffs involved in setting cash policies are important given the substantial levels of cash holdings by U.S. firms, and the potential consequences of cash holdings on future firm performance. Competition between firms, signaling, reputational concerns and learning suggest that firms will evaluate the policies of their peers when making decisions. This study has shown that firms incorporate the strategies of peer firms when deciding on how much cash to hold, and quantified the importance of this effect through the estimation of managers' evaluated costs of being different from their peers in terms of cash holdings. This is accomplished through estimation of a dynamic game where managers derive utility of being different from their peers in terms of cash holdings and external finance.

Peer effects are quantitatively important in understanding cash holdings, evident from the significant loss that firms assign to every incremental percentage point the fall below the peer group median cash-to-capital ratio. The baseline specification yields an evaluated cost equal approximately one percentage of operating income for every percentage point a firm is below the peer group median, while the most conservative estimation strategy results in a corresponding figure of 0.5 percent, which is economically significant. This magnitude vary with firms' environments consistent with key theoretical predictions: 
based on the baseline estimation strategy, for firms in industries with high (low) information asymmetry this cost is $1.16 \%(0.94 \%)$, while for industries with high (low) R\&D spending the cost is $0.67 \%(1.33 \%)$. When adding the estimated costs of cash holdings to an otherwise individual-agent model of cash holdings, there is a quantitatively significant change in firm behavior reducing the heterogeneity and skewness in corporate cash holdings. If firms did not take their peers into account when deciding on their cash holdings, firms' cash holdings would be much more dispersed than what we observe in the data. Overall, the estimated preferences of firms for holding cash depending on peer cash holdings establish peer effects as a quantitatively important economic force underlying firm behavior. 


\section{Bibliography}

Aguirregabiria, V., Mira, P. 2007. Sequential estimation of dynamic discrete games. Econometrica, 75, 1-53.

Anderson, R. W., Carverhill, A. 2012. Corporate liquidity and capital structure. Review of Financial Studies, 25, 797-837.

Bajari, P., Benkard, C. L., Levin, J. 2007. Estimating dynamic models of imperfect competition. Econometrica, 75, 1331-1370.

Bajari, P., Fruehwirth, J. C., Kim, K. i., Timmins, C. 2012. A rational expectations approach to hedonic price regressions with time-varying unobserved product attributes: The price of pollution. American Economic Review, 102, 1898-1926.

Bakke, T.-E., Gu, T. 2016. Diversification and cash dynamics. Journal of Financial Economics, forthcoming.

Bates, T. W., Chang, C. H., Chi, J. D. 2011. Why has the value of cash increased over time? Working paper.

Bates, T. W., Kahle, K. M., Stulz, R. M. 2009. Why Do U.S. Firms Hold So Much More Cash than They Used To? Journal of Finance, 64, 1985-2021. 
Bazdresch, S., Kahn, R. J., Whited, T. M. Estimating and testing dynamic corporate finance models. Review of Financial Studies, forthcoming.

Benoit, J.-P. 1984. Financially constrained entry in a game with incomplete information. The RAND Journal of Economics, 15, pp. 490-499.

Bernheim, B. D. 1994. A theory of conformity. Journal of Political Economy, 102, pp. 841-877.

Bolton, P., Scharfstein, D. S. 1990. A theory of predation based on agency problems in financial contracting. American Economic Review, 80, 93-106.

Brander, J., Lewis, T. 1986. Oligopoly and financial structure: The limited liability effect. American Economic Review, 76, 956-970.

Brown, S., Hillegeist, S. A. 2007. How disclosure quality affects the level of information asymmetry. Review of Accounting Studies, 12, 443-477.

Chen, Y.-W., Chang, Y. 2012. Peer effects on corporate cash holdings. Working Paper.

Chevalier, J. A., Scharfstein, D. S. 1996. Capital market imperfections and countercyclical markups: Theory and evidence. American Economic Review, 86, 703-725.

Chi, J. D., Su, X. 2016. Product market threats and the value of corporate cash holdings. Financial Management, 45, 705-735.

Chudson, W. A. 1945. The pattern of corporate financial structure: A cross-section view of manufacturing, mining, trade, and construction. National Bureau of Economic Research, New York.

Conlisk, J. 1980. Costly optimizers versus cheap imitators. Journal of Economic Behavior \& Organization, 1, 275-293. 
Cooper, R. W., Haltiwanger, J. C. 2006. On the nature of capital adjustment costs. Review of Economic Studies, 73, 611-633.

Decamps, J.-P., Mariotti, T., Rochet, J.-C., Villeneuve, S. 2011. Free cash flow, issuance costs, and stock prices. The Journal of Finance, 66, 1501-1544.

DeMarzo, P., Kaniel, R., Kremer, I. 2004. Diversification as a public good: Community effects in portfolio choice. Journal of Finance, 59, 1677-1716.

DeMarzo, P., Kaniel, R., Kremer, I. 2007. Technological innovation and real investment booms and busts. Journal of Financial Economics, 85, 735-754.

DeMarzo, P. M., Kaniel, R., Kremer, I. 2008. Relative wealth concerns and financial bubbles. Review of Financial Studies, 21, 19-50.

Denis, D. J., Sibilkov, V. 2010. Financial constraints, investment, and the value of cash holdings. Review of Financial Studies, 23, 247-269.

Dittmar, A., Mahrt-Smith, J. 2007. Corporate governance and the value of cash holdings. Journal of Financial Economics, 83, 599 - 634.

Drobetz, W., Grüninger, M. C., Hirschvogl, S. 2010. Information asymmetry and the value of cash. Journal of Banking \& Finance, 34, 2168-2184.

Eisfeldt, A. L., Muir, T. 2016. Aggregate issuance and savings waves. Journal of Monetary Economics, 84, 116-133.

Ellickson, P. B. 2007. Does sutton apply to supermarkets? RAND Journal of Economics, $38,43-59$.

Fama, E. F., French, K. R. 1997. Industry costs of equity. Journal of Financial Economics, 43, 153-193. 
Faulkender, M., Wang, R. 2006. Corporate financial policy and the value of cash. Journal of Finance, 61, 1957-1990.

Francis, B. B., Hasan, I., Kostova, G. L. 2016. When do peers matter?: A cross-country perspective

Fresard, L. 2010. Financial strength and product market behavior: The real effects of corporate cash holdings. Journal of Finance, 65, 1097-1122.

Gamba, A., Triantis, A. 2008. The value of financial flexibility. Journal of Finance, 63, 2263-2296.

Gao, X., Whited, T. M., Zhang, N. 2016. The interest sensitivity of corporate cash. Working Paper.

Grenadier, S. R., Malenko, A., Strebulaev, I. A. 2014. Investment busts, reputation, and the temptation to blend in with the crowd. Journal of Financial Economics, 111, 137-157.

Gu, T. 2016. U.s. multinationals and cash holdings. Journal of Financial Economics, forthcoming.

Harford, J. 1999. Corporate cash reserves and acquisitions. The Journal of Finance, 54, 1969-1997.

Harford, J., Mansi, S. A., Maxwell, W. F. 2008. Corporate governance and firm cash holdings in the us. Journal of Financial Economics, 87, 535-555.

Hartmann, W., Manchanda, P., Nair, H., Bothner, M., Dodds, P., Godes, D., Hosanagar, K., Tucker, C. 2008. Modeling social interactions: Identification, empirical methods and policy implications. Marketing Letters, 19, 287-304. 
Haushalter, D., Klasa, S., Maxwell, W. F. 2007. The influence of product market dynamics on a firm's cash holdings and hedging behavior. Journal of Financial Economics, 84, $797-825$.

Heckman, J. J., Robb, R. J. 1985. Alternative methods for evaluating the impact of interventions. In J. J. Heckman, B. S. Singer eds. Longitudinal Analysis of Labor Market Data, Cambridge University Press, 156 - 246, Cambridge Books Online.

Hennessy, C. A., Whited, T. M. 2005. Debt dynamics. Journal of Finance, 60, 1129-1165.

Hennessy, C. A., Whited, T. M. 2007. How costly is external financing? evidence from a structural estimation. Journal of Finance, 62, 1705-1745.

Hoberg, G., Phillips, G. 2010. Product market synergies and competition in mergers and acquisitions: A text-based analysis. Review of Financial Studies, 23, 3773-3811.

Hoberg, G., Phillips, G. 2016. Text-based network industries and endogenous product differentiation. Journal of Political Economy.

Hoberg, G., Phillips, G., Prabhala, N. 2014. Product market threats, payouts, and financial flexibility. Journal of Finance.

Hotz, V. J., Miller, R. A., Sanders, S., Smith, J. 1994. A simulation estimator for dynamic models of discrete choice. Review of Economic Studies, 61, 265-89.

Hugonnier, J., Malamud, S., Morellec, E. 2014. Capital supply uncertainty, cash holdings, and investment. Review of Financial Studies.

Imbens, G. W., Newey, W. K. 2009. Identification and estimation of triangular simultaneous equations models without additivity. Econometrica, 77, 1481-1512. 
Jensen, M. C. 1986. Agency costs of free cash flow, corporate finance, and takeovers. American Economic Review, 76, 323-29.

Jiang, Z., Lie, E. 2016. Cash holding adjustments and managerial entrenchment. Journal of Corporate Finance, 36, 190-205.

Kaustia, M., Rantala, V. 2015. Social learning and corporate peer effects. Journal of Financial Economics, 117, 653-669.

Keefe, M. O., Kieschnick, R. L. 2013. Why does the marginal value of cash to shareholders vary over time? Working paper.

Kisser, M. 2013. The real option value of cash. Review of Finance, 17, 1649-1697.

Klasa, S., Maxwell, W. F., Ortiz-Molina, H. 2009. The strategic use of corporate cash holdings in collective bargaining with labor unions. Journal of Financial Economics, $92,421-442$.

Larkin, Y. 2013. Brand perception, cash flow stability, and financial policy. Journal of Financial Economics, 110, 232-253.

Leary, M. T., Roberts, M. R. 2014. Do peer firms affect corporate financial policy? Journal of Finance, 69, 139-178.

Manski, C. F. 1993. Identification of endogenous social effects: The reflection problem. Review of Economic Studies, 60, 531-42.

Matvos, G. 2013. Estimating the benefits of contractual completeness. Review of Financial Studies, 26, 2798-2844. 
Matvos, G., Seru, A. 2014. Resource allocation within firms and financial market dislocation: Evidence from diversified conglomerates. Review of Financial Studies, 27, 1143-1189.

Misra, S., Nair, H. 2011. A structural model of sales-force compensation dynamics: Estimation and field implementation. Quantitative Marketing and Economics, 9, 211-257.

Morellec, E., Nikolov, B., Zucchi, F. 2013. Competition, cash holdings, and financing decisions. Swiss Finance Institute Research Paper, 13.

Murfin, J., Pratt, R. 2017. Who finances durable goods and why it matters: Captive finance and the coase conjecture. Working Paper.

Nikolov, B., Whited, T. M. 2014. Agency conflicts and cash: Estimates from a dynamic model. Journal of Finance, 69, 1883-1921.

Opler, T., Pinkowitz, L., Stulz, R., Williamson, R. 1999. The determinants and implications of corporate cash holdings. Journal of Financial Economics, 52, 3-46.

Pakes, A., Ostrovsky, M., Berry, S. 2007. Simple estimators for the parameters of discrete dynamic games (with entry/exit examples). RAND Journal of Economics, 38, 373-399.

Pesendorfer, M., Schmidt-Dengler, P. 2008. Asymptotic Least Squares Estimators for Dynamic Games -super-1. Review of Economic Studies, 75, 901-928.

Pinkowitz, L., Williamson, R. 2001. Bank power and cash holdings: Evidence from japan. Review of Financial Studies, 14, 1059-82.

Popadak, J. A. 2017. Dividend payments as a response to peer influence. Working paper.

Riddick, L. A., Whited, T. M. 2009. The corporate propensity to save. Journal of Finance, 64, 1729-1766. 
Scharfstein, D. S., Stein, J. C. 1990. Herd behavior and investment. Amercian Economic Review, 80, 465-479.

Storn, R., Price, K. 1997. Differential evolution - a simple and efficient heuristic for global optimization over continuous spaces. Journal of Global Optimization, 11, 341-359.

Strebulaev, I. A., Whited, T. M. 2012. Dynamic models and structural estimation in corporate finance. Foundations and Trends(R) in Finance, 6, 1-163.

Sutton, J. 1991. Sunk Costs and Market Structure. The MIT Press.

Warusawitharana, M. 2015. Research and development, profits and firm value: A structural estimation. Quantitative Economics, 6, 531-565.

Weintraub, G. Y., Benkard, C. L., Van Roy, B. 2006. Oblivious equilibrium: A mean field approximation for large scale dynamic games. Advances in Neural Information Processing Systems, 18.

Weintraub, G. Y., Benkard, C. L., Van Roy, B. 2008. Markov perfect industry dynamics with many firms. Econometrica, 76, 1375-1411.

Weintraub, G. Y., Benkard, C. L., Van Roy, B. 2010. Computational methods for oblivious equilibrium. Operations Research, 58, 1247-1265.

Whited, T. M. 2006. External finance constraints and the intertemporal pattern of intermittent investment. Journal of Financial Economics, 81, 467-502. 


\section{Table 1: Summary statistics}

This table contains summary statistics for the primary variables of the sample used for the main estimation, consisting of 16094 firm-year observations from the Compustat database for 109 peer groups during the 1972 to 2015 period, resulting from sample selection criteria as outlined in section 3.1.1. The statistics shown are means, standard deviations (Std. Dev.), as well as $25^{t h}, 50^{t h}$ and $75^{\text {th }}$ percentiles (P25, P50 and P75, respectively). Panel A contains information for the full sample, while panels B an contain information for the second and first half of the sample period, respectively.

Panel A: Full Sample

\begin{tabular}{lrrrrrr}
\hline \hline Variable & Obs & Mean & Std. Dev. & P25 & P50 & P75 \\
\hline Level values & & & & & & \\
Assets & & & & & & \\
Capital & 16094 & 3944 & 20179 & 50 & 213 & 1222 \\
Variables scaled by beginning-of-period Capital & & & & & \\
Cash & 16094 & 2048 & 10099 & 23 & 111 & 662 \\
Profitability & 16094 & .34 & .62 & .05 & .13 & .35 \\
Investment & 16094 & .3 & .37 & .14 & .27 & .45 \\
ExternalFinance & 16094 & .11 & .09 & .05 & .09 & .15 \\
Variables scaled by beginning-of-period Assets & & & & & \\
Capital & 16094 & 0.002 & .27 & -.09 & -.03 & .03 \\
Cash & 16094 & .606 & .326 & .372 & .549 & .786 \\
Profitability & 16094 & .129 & .16 & .028 & .073 & .174 \\
Investment & 16094 & .138 & .138 & .082 & .143 & .208 \\
ExternalFinance & 16094 & .059 & .053 & .024 & .045 & .077 \\
& 16094 & -.0005 & .116 & -.047 & -.017 & .016 \\
\hline
\end{tabular}

Panel B: Sample period 1994 - 2015, scaling by beginning-of-period Capital

\begin{tabular}{lrrrrrr}
\hline \hline Variable & Obs & Mean & Std. Dev. & P25 & P50 & P75 \\
\hline Cash & 6412 & .53 & .83 & .07 & .21 & .61 \\
Profitability & 6412 & .26 & .44 & .12 & .25 & .45 \\
Investment & 6412 & .1 & .08 & .05 & .08 & .13 \\
ExternalFinance & 6412 & 0.003 & .32 & -.11 & -.02 & .03 \\
\hline
\end{tabular}

Panel C: Sample period 1972 - 1993, scaling by beginning-of-period Capital

\begin{tabular}{lrrrrrr}
\hline \hline Variable & Obs & Mean & Std. Dev. & P25 & P50 & P75 \\
\hline Cash & 9682 & .22 & .38 & .04 & .1 & .24 \\
Profitability & 9682 & .32 & .31 & .16 & .28 & .45 \\
Investment & 9682 & .12 & .09 & .06 & .1 & .16 \\
ExternalFinance & 9682 & 0.001 & .23 & -.08 & -.03 & .03 \\
\hline
\end{tabular}




\section{Table 2: Determinants of the Persistence of Cash Incentive Shocks}

This table shows estimated coefficients from OLS regressions with the persistence of the unobserved component of the marginal value of cash $\mu_{t, t+1}^{j}$ as the dependent variable, and industry characteristics as the independent variables. The dependent variable is estimated at the 3-digit SIC code level and is assumed to be constant over time. The independent variables based on firm characteristics are correspondingly calculated as pooled average values or standard deviations for state variables or other firm/market characteristics over firms and time within each group of firms. Leverage is market leverage calculated as (Total Assets Book Value of Equity)/(Total Assets - Book Value of Equity + Market Value of Equity), MB is the marketto-book ratio calculated as ((Total Assets-(Total Assets-Total Liabilities+Deferred Taxes and Investment Tax Credit) $+($ Market Value of Equity))/Total Assets.), $R \& D$ is research and development expenses scaled by total assets, and ZScore is Altman's Z-Score calculated as 1.2*Working Capital/Total Assets + 1.4*Retained Earnings/Total Assets $+3.3 *$ Earnings Before Interest \& Tax/Total Assets $+0.6 *$ Market Value of Equity/Total Liabilities $+0.999 *$ Sales/Total Assets. Missing values for research and development have been replaced by zero. Significance at the $10 \%, 5 \%$, and $1 \%$ level is indicated by *,**, and ***, respectively. Standard errors are shown in parentheses.

\begin{tabular}{|c|c|c|c|c|c|}
\hline & (1) & (2) & (3) & (4) & (5) \\
\hline \multicolumn{6}{|c|}{ Means: State Variables } \\
\hline Cash & $\begin{array}{l}0.045 \\
(0.13)\end{array}$ & & $\begin{array}{l}0.114 \\
(0.37)\end{array}$ & $\begin{array}{l}0.355 \\
(0.41)\end{array}$ & $\begin{array}{l}0.355 \\
(0.42)\end{array}$ \\
\hline Profitability & $\begin{array}{c}-0.152 \\
(0.26)\end{array}$ & & $\begin{array}{c}-0.217 \\
(0.31)\end{array}$ & $\begin{array}{l}-0.202 \\
(0.32)\end{array}$ & $\begin{array}{c}-0.331 \\
(0.36)\end{array}$ \\
\hline Investment & $\begin{array}{l}1.618 \\
(1.26)\end{array}$ & & $\begin{array}{l}1.614 \\
(1.61)\end{array}$ & $\begin{array}{l}2.636 \\
(1.74)\end{array}$ & $\begin{array}{l}3.024 \\
(1.81)\end{array}$ \\
\hline ExtFin & $\begin{array}{l}0.487 \\
(0.65)\end{array}$ & & $\begin{array}{c}-0.195 \\
(0.85)\end{array}$ & $\begin{array}{l}0.377 \\
(0.91)\end{array}$ & $\begin{array}{l}0.298 \\
(1.03)\end{array}$ \\
\hline$E[\xi]$ & $\begin{array}{l}0.031 \\
(0.06)\end{array}$ & & $\begin{array}{c}-0.009 \\
(0.06)\end{array}$ & $\begin{array}{c}-0.015 \\
(0.06)\end{array}$ & $\begin{array}{c}-0.020 \\
(0.08)\end{array}$ \\
\hline \multicolumn{6}{|c|}{ Standard Deviations: State Variables } \\
\hline Cash & & $\begin{array}{c}-0.287 * * \\
(0.13)\end{array}$ & $\begin{array}{l}-0.351 \\
(0.24)\end{array}$ & $\begin{array}{l}-0.366 \\
(0.25)\end{array}$ & $\begin{array}{r}-0.273 \\
(0.28)\end{array}$ \\
\hline Profitability & & $\begin{array}{l}0.240 \\
(0.28)\end{array}$ & $\begin{array}{l}0.285 \\
(0.32)\end{array}$ & $\begin{array}{l}0.329 \\
(0.32)\end{array}$ & $\begin{array}{l}0.098 \\
(0.39)\end{array}$ \\
\hline Investment & & $\begin{array}{c}2.398^{* *} \\
(1.18)\end{array}$ & $\begin{array}{l}1.129 \\
(1.70)\end{array}$ & $\begin{array}{l}0.318 \\
(1.72)\end{array}$ & $\begin{array}{l}0.214 \\
(1.81)\end{array}$ \\
\hline ExtFin & & $\begin{array}{l}0.389 \\
(0.32)\end{array}$ & $\begin{array}{l}0.435 \\
(0.41)\end{array}$ & $\begin{array}{l}0.398 \\
(0.44)\end{array}$ & $\begin{array}{l}0.622 \\
(0.50)\end{array}$ \\
\hline$E[\xi]$ & & $\begin{array}{c}0.088^{* *} \\
(0.04)\end{array}$ & $\begin{array}{c}0.086^{* * *} \\
(0.04)\end{array}$ & $\begin{array}{c}0.096 * * \\
(0.04)\end{array}$ & $\begin{array}{c}0.126^{* *} * \\
(0.06)\end{array}$ \\
\hline \multicolumn{6}{|c|}{ Standard Deviations: State Variables } \\
\hline$M B$ & & & & $\begin{array}{l}-0.094 \\
(0.10)\end{array}$ & $\begin{array}{l}0.018 \\
(0.12)\end{array}$ \\
\hline Leverage & & & & $\begin{array}{l}-0.562 \\
(0.41)\end{array}$ & $\begin{array}{c}-0.446 \\
(0.45)\end{array}$ \\
\hline ZScore & & & & $\begin{array}{l}-0.036 \\
(0.03)\end{array}$ & $\begin{array}{c}-0.059 \\
(0.04)\end{array}$ \\
\hline$R \& D$ & & & & $\begin{array}{c}-2.461 * * \\
(1.10)\end{array}$ & $\begin{array}{c}-2.088^{*} \\
(1.22)\end{array}$ \\
\hline Fluidity & & & & & $\begin{array}{c}-0.040 * \\
(0.02)\end{array}$ \\
\hline$H H I$ & & & & & $\begin{array}{c}-0.133 \\
(0.21)\end{array}$ \\
\hline$N$ & 71 & 71 & 71 & 71 & 66 \\
\hline$R^{2}$ & 0.087 & 0.194 & 0.211 & 0.294 & 0.337 \\
\hline
\end{tabular}




\section{Table 3: Predictions Based on Estimated Policy Functions}

This table shows predicted firm investment, cash, profitability and external finance. The statistics are calculated based on initial states defined by all states in the data. For example, the average investment at $t=3$ is the cross-sectional average of expected investment three years in the future in a pooled sample with all observed states defining starting values. Time series are calculated as average time series over 500 simulations analogously to the procedure for calculating firm value as explained in Section 3.2.1.

\begin{tabular}{lccccc}
\hline \hline & $\mathrm{t}=0$ & $\mathrm{t}=3$ & $\mathrm{t}=5$ & $\mathrm{t}=10$ & $\mathrm{t}=50$ \\
\hline Investment & & & & & \\
Mean & 0.11 & 0.08 & 0.08 & 0.08 & 0.09 \\
Std. dev. & 0.09 & 0.08 & 0.05 & 0.02 & 0.01 \\
& & & & & \\
Cash & & & & & \\
Mean & 0.34 & 0.41 & 0.51 & 0.64 & 0.83 \\
Std. dev. & 0.62 & 0.46 & 0.46 & 0.36 & 0.22 \\
& & & & & \\
Profitability & & & & & \\
Mean & 0.30 & 0.32 & 0.32 & 0.31 & 0.31 \\
Std. dev. & 0.37 & 0.17 & 0.11 & 0.05 & 0.02 \\
External Finance & & & & & \\
Mean & 0.002 & 0.05 & 0.001 & 0.002 & 0.01 \\
Std. dev. & 0.27 & 0.22 & 0.12 & 0.07 & 0.05 \\
& & & & & \\
\hline \hline
\end{tabular}




\section{Table 4: Structural Parameter Estimates: Preliminary Specification}

This table contains estimates of the structural parameters of the model, with bootstrapped standard errors given in parentheses. The sample consists of 16094 firm-year observations from the Compustat database for 109 peer groups during the 1972 to 2015 period, resulting from sample selection criteria as outlined in section 3.1.1.Each parameter is identified by its corresponding model component in the following utility function:

$$
\begin{aligned}
& u_{i, t-1}^{j}=z_{i, t}^{j} k_{i, t}^{j}-I_{i, t}^{j}-\mathcal{I}_{I_{i, t}^{j}>0}\left(\phi_{I, 1}^{j} K_{i, t}^{j}+\phi_{I, 2}^{j}\left(\frac{I_{i, t}^{j}}{K_{i, t}^{j}}\right)^{2}\right)-\mathcal{I}_{e_{i, t}^{j}>0}\left(\phi_{e, 1}^{j} e_{i, t}^{j}\right)-\mathcal{I}_{p_{i, t}^{j}>0}\left(\phi_{p, 1}^{j} p_{i, t}^{j}+\left(10^{6}\right) \phi_{p, \xi}^{j} \xi_{i, t}^{j}\right) \\
& -\mathcal{I}_{A} \gamma_{p, 1}^{j}\left|\frac{p_{i, t}^{j}}{k_{i, t}^{j}}-\widetilde{\left(\frac{p}{k}\right)_{-i, t}^{j}}\right|-\mathcal{I}_{B} \gamma_{p, 2}^{j}\left|\frac{p_{i, t}^{j}}{k_{i, t}^{j}}-\widetilde{\left(\frac{p}{k}\right)_{-i, t}^{j}}\right|
\end{aligned}
$$

where $z_{i, t}^{j}$ if the profitability of firm $i$ in industry $j$ at time $t, k_{i, t}^{j}$ is capital, $I_{i, t}^{j}$ is investment, $e_{i, t}^{j}$ is external finance, $p_{i, t}^{j}$ is cash, $\mathcal{I}_{A}$ is an indicator variable for condition $A$ being true, and $\xi_{i, t}^{j}$ is a state variable for incentives to hold cash. Peer parameters are denoted by $\gamma$ and intra-firm cost associated with external finance, cash and investment are denoted by $\phi$. Panel B contains results for the main estimation that includes $\xi_{i, t}^{j}$, the state variable for incentives to hold cash not captured by the model, in addition to the other parameters also included in the specification as shown in Panel A.

Panel A

\begin{tabular}{ccccccc}
\hline \multicolumn{3}{c}{ Peer Parameters } & \multicolumn{5}{c}{ Intra-firm Parameters } \\
$\gamma_{p, 1}^{j}$ & $\gamma_{p, 2}^{j}$ & $\phi_{e, 1}^{j}$ & $\phi_{p, 0}^{j}$ & $\phi_{I, 1}^{j}$ & $\phi_{I, 2}^{j}$ & \\
\hline 89.16 & -78.71 & 0.08 & 0.01 & 0.12 & 647.71 & \\
$(1.08)$ & $(0.99)$ & $(0.0024)$ & $(0.001)$ & $(0.00044)$ & $(11.06)$ & \\
\multicolumn{7}{c}{ Panel B } \\
\multicolumn{7}{c}{ Intra-firm Parameters } \\
\hline \multicolumn{7}{c}{ Peer Parameters } \\
$\gamma_{p, 1}^{j}$ & $\gamma_{p, 2}^{j}$ & $\phi_{e, 1}^{j}$ & $\phi_{p, 0}^{j}$ & $\phi_{p, \xi}^{j}$ & $\phi_{I, 1}^{j}$ & $\phi_{I, 2}^{j}$ \\
\hline 99.28 & -81.26 & 0.10 & -0.025 & 3.31 & 0.11 & 1072 \\
$(1.11)$ & $(0.96)$ & $(0.0021)$ & $(0.001)$ & $(0.1)$ & $(0.00054)$ & $(18.1)$ \\
\hline \hline
\end{tabular}




\section{Table 5: Structural Parameter Estimates: Main Specification}

This table contains estimates of the structural parameters of the model, with bootstrapped standard errors given in parentheses. The sample consists of 16094 firm-year observations from the Compustat database for 109 peer groups during the 1972 to 2015 period, resulting from sample selection criteria as outlined in section 3.1.1.Each parameter is identified by its corresponding model component in the following utility functions:

Panel A utility function:

$$
\begin{aligned}
& u_{i, t-1}^{j}=z_{i, t}^{j} k_{i, t}^{j}-I_{i, t}^{j}-\mathcal{I}_{I_{i, t}^{j}>0}\left(\phi_{I, 1}^{j} K_{i, t}^{j}+\phi_{I, 2}^{j}\left(\frac{I_{i, t}^{j}}{K_{i, t}^{j}}\right)^{2}\right)-\mathcal{I}_{e_{i, t}^{j}>0}\left(\phi_{e, 1}^{j} e_{i, t}^{j}\right)-\mathcal{I}_{p_{i, t}^{j}>0}\left(\phi_{p, 1}^{j} p_{i, t}^{j}+\left(10^{6}\right) \phi_{p, \xi}^{j} \xi_{i, t}^{j}\right) \\
& -\mathcal{I}_{A} \gamma_{p, 1}^{j} z_{i, t}^{j} k_{i, t}^{j}\left|\frac{p_{i, t}^{j}}{k_{i, t}^{j}}-\widetilde{\left(\frac{p}{k}\right)_{-i, t}^{j}}\right|-\mathcal{I}_{B} \gamma_{p, 2}^{j} z_{i, t}^{j} k_{i, t}^{j}\left|\frac{p_{i, t}^{j}}{k_{i, t}^{j}}-\widetilde{\left(\frac{p}{k}\right)_{-i, t}^{j}}\right|
\end{aligned}
$$

Panel B utility function:

$$
\begin{aligned}
& u_{i, t-1}^{j}=z_{i, t}^{j} k_{i, t}^{j}-I_{i, t}^{j}-\mathcal{I}_{I_{i, t}^{j}>0}\left(\phi_{I, 1}^{j} K_{i, t}^{j}+\phi_{I, 2}^{j}\left(\frac{I_{i, t}^{j}}{K_{i, t}^{j}}\right)^{2}\right)-\mathcal{I}_{e_{i, t}^{j}>0}\left(\phi_{e, 1}^{j} e_{i, t}^{j}\right)-\mathcal{I}_{p_{i, t}^{j}>0}\left(\phi_{p, 1}^{j} p_{i, t}^{j}+\left(10^{6}\right) \phi_{p, \xi}^{j} \xi_{i, t}^{j}\right) \\
& -\mathcal{I}_{A} \gamma_{p, 1}^{j} k_{i, t}^{j}\left|\frac{p_{i, t}^{j}}{k_{i, t}^{j}}-\widetilde{\left(\frac{p}{k}\right)_{-i, t}^{j}}\right|-\mathcal{I}_{B} \gamma_{p, 2}^{j} k_{i, t}^{j}\left|\frac{p_{i, t}^{j}}{k_{i, t}^{j}}-\widetilde{\left(\frac{p}{k}\right)_{-i, t}^{j}}\right|
\end{aligned}
$$

where $z_{i, t}^{j}$ if the profitability of firm $i$ in industry $j$ at time $t, k_{i, t}^{j}$ is capital, $I_{i, t}^{j}$ is investment, $e_{i, t}^{j}$ is external finance, $p_{i, t}^{j}$ is cash, $\mathcal{I}_{A}$ is an indicator variable for condition $A$ being true, and $\xi_{i, t}^{j}$ is a state variable for incentives to hold cash. Peer parameters are denoted by $\gamma$ and intra-firm cost associated with external finance, cash and investment are denoted by $\phi$. Panel B contains results for the main estimation that includes $\xi_{i, t}^{j}$, the state variable for incentives to hold cash not captured by the model, in addition to the other parameters also included in the specification as shown in Panel A.

Panel A: Costs as Fraction of Operating Income

\begin{tabular}{ccccccc}
\hline \multicolumn{3}{c}{ Peer Parameters } & \multicolumn{5}{c}{ Intra-firm Parameters } \\
$\gamma_{p, 1}^{j}$ & $\gamma_{p, 2}^{j}$ & $\phi_{e, 1}^{j}$ & $\phi_{p, 0}^{j}$ & $\phi_{p, \xi}^{j}$ & $\phi_{I, 1}^{j}$ & $\phi_{I, 2}^{j}$ \\
\hline 0.87 & 1.003 & 0.079 & -0.011 & 1.88 & 0.12 & 100.134 \\
$(0.011)$ & $(0.014)$ & $(0.002)$ & $(0.0013)$ & $(0.13)$ & $(0.0006)$ & $(3.64)$
\end{tabular}

Panel B: Costs as Fraction of Capital

\begin{tabular}{ccccccc}
\hline \multicolumn{3}{c}{ Peer Parameters } & \multicolumn{5}{c}{ Intra-firm Parameters } \\
$\gamma_{p, 1}^{j}$ & $\gamma_{p, 2}^{j}$ & $\phi_{e, 1}^{j}$ & $\phi_{p, 0}^{j}$ & $\phi_{p, \xi}^{j}$ & $\phi_{I, 1}^{j}$ & $\phi_{I, 2}^{j}$ \\
\hline 0.38 & 0.236 & 0.044 & -0.03 & 1.87 & 0.15 & 101.662 \\
$(0.0036)$ & $(0.0036)$ & $(0.0024)$ & $(0.0013)$ & $(0.14)$ & $(0.001)$ & $(3.86)$ \\
\hline \hline
\end{tabular}




\section{Table 6: Structural Parameter Estimates: Parameter Heterogeneity}

This table contains estimates of the structural parameters of the model for subgroups of the sample as defined by the variables in the first data row table below, with bootstrapped standard errors given in parentheses. Each subgroup is defined by the sample median, i.e. the "High" subgroup is the set of observations with above median values for the characteristic under study. The sample consists of 16094 firm-year observations from the Compustat database for 109 peer groups during the 1972 to 2015 period, resulting from sample selection criteria as outlined in section 3.1.1.Each parameter is identified by its corresponding model component in the following utility function:

$$
\begin{aligned}
& u_{i, t-1}^{j}=z_{i, t}^{j} k_{i, t}^{j}-I_{i, t}^{j}-\mathcal{I}_{I_{i, t}^{j}>0}\left(\phi_{I, 1}^{j} K_{i, t}^{j}+\phi_{I, 2}^{j}\left(\frac{I_{i, t}^{j}}{K_{i, t}^{j}}\right)^{2}\right)-\mathcal{I}_{e_{i, t}^{j}>0}\left(\phi_{e, 1}^{j} e_{i, t}^{j}\right)-\mathcal{I}_{p_{i, t}^{j}>0}\left(\phi_{p, 1}^{j} p_{i, t}^{j}+\left(10^{6}\right) \phi_{p, \xi}^{j} \xi_{i, t}^{j}\right) \\
& -\mathcal{I}_{A} \gamma_{p, 1}^{j}\left|\frac{p_{i, t}^{j}}{k_{i, t}^{j}}-\widetilde{\left(\frac{p}{k}\right)_{-i, t}^{j}}\right|-\mathcal{I}_{B} \gamma_{p, 2}^{j}\left|\frac{p_{i, t}^{j}}{k_{i, t}^{j}}-\widetilde{\left(\frac{p}{k}\right)_{-i, t}^{j}}\right|
\end{aligned}
$$

where $z_{i, t}^{j}$ if the profitability of firm $i$ in industry $j$ at time $t, k_{i, t}^{j}$ is capital, $I_{i, t}^{j}$ is investment, $e_{i, t}^{j}$ is external finance, $p_{i, t}^{j}$ is cash, $\mathcal{I}_{A}$ is an indicator variable for condition $A$ being true, and $\xi_{i, t}^{j}$ is a state variable for incentives to hold cash. Peer parameters are denoted by $\gamma$ and intra-firm cost

\begin{tabular}{|c|c|c|c|c|c|c|c|c|}
\hline & \multicolumn{2}{|c|}{$H H I$} & \multicolumn{2}{|c|}{$R \& D$} & \multicolumn{2}{|c|}{$P I N$} & \multicolumn{2}{|c|}{$\operatorname{Tax}$} \\
\hline & High & Low & High & Low & High & Low & High & Low \\
\hline & 1.03 & 0.69 & 0.61 & 1.13 & 0.98 & 0.82 & 1.16 & 0.69 \\
\hline & 1.11 & 0.91 & 0.67 & 1.33 & 1.16 & 0.94 & 1.19 & 0.92 \\
\hline
\end{tabular}
associated with external finance, cash and investment are denoted by $\phi$. 


\section{Table 7: Sensitivity to the Cost of Investment}

This table contains estimates of the structural parameters of the model, with the investment cost parameter set equal to different pre-specified levels before running the optimization routine, treating this parameter value as known. The sample consists of 16094 firm-year observations from the Compustat database for 109 peer groups during the 1972 to 2015 period, resulting from sample selection criteria as outlined in section 3.1.1. In Panel A I show results from an estimation where there is only a fixed cost of investment. In Panel B, the row whose first element is $\frac{\Delta \phi_{I, 1}^{j}}{\phi_{I, 1}^{j}}$ specifies the percentage change in the first component of the cost of investment, and the two subsequent rows shows the associated estimated peer effects parameters of cash. Panel $\mathrm{C}$ contains results from an analogous exercise studying the effect of the quadratic investment cost component. Each parameter is identified by its corresponding model component in the following utility function:

$$
\begin{aligned}
& u_{i, t-1}^{j}=z_{i, t}^{j} k_{i, t}^{j}-I_{i, t}^{j}-\mathcal{I}_{I_{i, t}^{j}>0}\left(\phi_{I, 1}^{j} K_{i, t}^{j}+\phi_{I, 2}^{j}\left(\frac{I_{i, t}^{j}}{K_{i, t}^{j}}\right)^{2}\right)-\mathcal{I}_{e_{i, t}^{j}>0}\left(\phi_{e, 1}^{j} e_{i, t}^{j}\right)-\mathcal{I}_{p_{i, t}^{j}>0}\left(\phi_{p, 1}^{j} p_{i, t}^{j}+\left(10^{6}\right) \phi_{p, \xi}^{j} \xi_{i, t}^{j}\right) \\
& -\mathcal{I}_{A} \gamma_{p, 1}^{j} z_{i, t}^{j} k_{i, t}^{j}\left|\frac{p_{i, t}^{j}}{k_{i, t}^{j}}-\widetilde{\left(\frac{p}{k}\right)_{-i, t}^{j}}\right|-\mathcal{I}_{B} \gamma_{p, 2}^{j} z_{i, t}^{j} k_{i, t}^{j}\left|\frac{p_{i, t}^{j}}{k_{i, t}^{j}}-\widetilde{\left(\frac{p}{k}\right)_{-i, t}^{j}}\right|
\end{aligned}
$$

where $z_{i, t}^{j}$ if the profitability of firm $i$ in industry $j$ at time $t, k_{i, t}^{j}$ is capital, $I_{i, t}^{j}$ is investment, $e_{i, t}^{j}$ is external finance, $p_{i, t}^{j}$ is cash, $\mathcal{I}_{A}$ is an indicator variable for condition $A$ being true, and $\xi_{i, t}^{j}$ is a state variable for incentives to hold cash. Peer parameters are denoted by $\gamma$ and intra-firm cost associated with external finance, cash and investment are denoted by $\phi$.

Panel A: Fixed investment cost only

\begin{tabular}{cccccc}
\hline \multicolumn{2}{c}{ Peer Parameters } & \multicolumn{5}{c}{ Intra-firm Parameters } \\
$\gamma_{p, 1}^{j}$ & $\gamma_{p, 2}^{j}$ & $\phi_{e, 1}^{j}$ & $\phi_{p, 0}^{j}$ & $\phi_{p, \xi}^{j}$ & $\phi_{I, 1}^{j}$ \\
\hline 0.87 & 1.006 & 0.07 & -0.006 & 1.64 & 0.126 \\
$(0.01)$ & $(0.014)$ & $(0.0023)$ & $(0.0013)$ & $(0.12)$ & $(0.00062)$
\end{tabular}

Panel B: Sensitivity of cash peer effect parameters to fixed cost

\begin{tabular}{ccccccccc}
\hline$\frac{\Delta \phi_{I, 1}^{j}}{\phi_{I, 1}^{j}}$ & $-50 \%$ & $-25 \%$ & $-10 \%$ & $-5 \%$ & $5 \%$ & $10 \%$ & $25 \%$ & $50 \%$ \\
\hline$\gamma_{p, 1}^{j}$ & 0.676 & 0.736 & 0.808 & 0.838 & 0.914 & 0.958 & 1.117 & 1.452 \\
$\gamma_{p, 2}^{j}$ & 1.774 & 1.335 & 1.129 & 1.063 & 0.947 & 0.901 & 0.788 & 0.688
\end{tabular}

Panel C: Sensitivity of cash peer effect parameters to quadratic cost

\begin{tabular}{ccccccccc}
\hline$\frac{\Delta \phi_{I, 2}^{j}}{\phi_{I, 2}^{j}}$ & $-50 \%$ & $-25 \%$ & $-10 \%$ & $-5 \%$ & $5 \%$ & $10 \%$ & $25 \%$ & $50 \%$ \\
\hline$\gamma_{p, 1}^{j}$ & 0.869 & 0.871 & 0.872 & 0.873 & 0.874 & 0.875 & 0.876 & 0.877 \\
$\gamma_{p, 2}^{j}$ & 1.002 & 1.002 & 1.002 & 1.002 & 1.002 & 1.003 & 1.003 & 1.002 \\
\hline \hline
\end{tabular}




\section{Table 8: Sensitivity to the Cost of External Finance}

This table contains estimates of the structural parameters of the model, with the external finance cost parameters set equal to different pre-specified levels before running the optimization routine, treating this parameter value as known. The sample consists of 16094 firm-year observations from the Compustat database for 109 peer groups during the 1972 to 2015 period, resulting from sample selection criteria as outlined in section 3.1.1. Panel A contains estimation results stemming from a utility specification where there are peer effects in external finance decisions. In Panel B, the row whose first element is $\frac{\Delta \phi_{e, 1}^{j}}{\phi_{e, 1}^{j}}$ specifies the percentage change in the cost of obtaining external finance, and the two subsequent rows shows the associated estimated peer effects parameters of cash. Each parameter is identified by its corresponding model component in the following utility function:

$$
\begin{aligned}
u_{i, t-1}^{j}= & z_{i, t}^{j} k_{i, t}^{j}-I_{i, t}^{j}-\mathcal{I}_{I_{i, t}^{j}>0}\left(\phi_{I, 1}^{j} K_{i, t}^{j}+\phi_{I, 2}^{j}\left(\frac{I_{i, t}^{j}}{K_{i, t}^{j}}\right)^{2}\right)-\mathcal{I}_{e_{i, t}^{j}>0}\left(\phi_{e, 1}^{j} e_{i, t}^{j}\right)-\mathcal{I}_{p_{i, t}^{j}>0}\left(\phi_{p, 1}^{j} p_{i, t}^{j}+\left(10^{6}\right) \phi_{p, \xi}^{j} \xi_{i, t}^{j}\right) \\
& -\mathcal{I}_{A} \gamma_{p, 1}^{j} z_{i, t}^{j} k_{i, t}^{j}\left|\frac{p_{i, t}^{j}}{k_{i, t}^{j}}-\widetilde{\left(\frac{p}{k}\right)_{-i, t}^{j}}\right|-\mathcal{I}_{B} \gamma_{p, 2}^{j} z_{i, t}^{j} k_{i, t}^{j}\left|\frac{p_{i, t}^{j}}{k_{i, t}^{j}}-\widetilde{\left(\frac{p}{k}\right)_{-i, t}^{j}}\right| \\
& -\mathcal{I}_{A} \gamma_{e, 1}^{j} z_{i, t}^{j} k_{i, t}^{j}\left|\frac{e_{i, t}^{j}}{k_{i, t}^{j}}-\widetilde{\left(\frac{e}{k}\right)_{-i, t}^{j}}\right|-\mathcal{I}_{B} \gamma_{e, 2}^{j} z_{i, t}^{j} k_{i, t}^{j}\left|\frac{e_{i, t}^{j}}{k_{i, t}^{j}}-\widetilde{\left(\frac{e}{k}\right)_{-i, t}^{j}}\right|
\end{aligned}
$$

where $z_{i, t}^{j}$ if the profitability of firm $i$ in industry $j$ at time $t, k_{i, t}^{j}$ is capital, $I_{i, t}^{j}$ is investment, $e_{i, t}^{j}$ is external finance, $p_{i, t}^{j}$ is cash, $\mathcal{I}_{A}$ is an indicator variable for condition $A$ being true, and $\xi_{i, t}^{j}$ is a state variable for incentives to hold cash. Peer parameters are denoted by $\gamma$ and intra-firm cost associated with external finance, cash and investment are denoted by $\phi$. The sensitivity analysis in Panel B is based on the estimation in Panel A of Table 5.

Panel A: Estimation with peer effects in external finance

\begin{tabular}{ccccccccc}
\hline \multicolumn{4}{c}{ Peer Parameters } & \multicolumn{5}{c}{ Intra-firm Parameters } \\
$\gamma_{p, 1}^{j}$ & $\gamma_{p, 2}^{j}$ & $\gamma_{e, 1}^{j}$ & $\gamma_{e, 2}^{j}$ & $\phi_{e, 1}^{j}$ & $\phi_{p, 0}^{j}$ & $\phi_{p, \xi}^{j}$ & $\phi_{I, 1}^{j}$ & $\phi_{I, 2}^{j}$ \\
\hline 1.05 & 1.48 & 0.64 & 1.67 & 0.034 & 0.16 & 1.1 & 0.089 & 62.06 \\
$(0.014)$ & $(0.024)$ & $(0.021)$ & $(0.026)$ & $(0.005)$ & $(0.0033)$ & $(0.18)$ & $(0.001)$ & $(3.47)$ \\
\hline
\end{tabular}

Panel B: Sensitivity of cash peer effect parameters

\begin{tabular}{ccccccccc}
\hline$\frac{\Delta \phi_{e, 2}^{j}}{\phi_{e, 2}^{j}}$ & $-50 \%$ & $-25 \%$ & $-10 \%$ & $-5 \%$ & $5 \%$ & $10 \%$ & $25 \%$ & $50 \%$ \\
\hline$\gamma_{p, 1}^{j}$ & 0.877 & 0.875 & 0.873 & 0.874 & 0.873 & 0.873 & 0.874 & 0.879 \\
$\gamma_{p, 2}^{j}$ & 0.987 & 0.994 & 0.997 & 1.000 & 1.004 & 1.007 & 1.015 & 1.030 \\
\hline \hline
\end{tabular}




\section{Table 9: Structural Parameter Estimates Based on Data Not Explained by Common Cross-Sectional Determinants of Cash Holdings}

This table contains estimates of the structural parameters of the model, with bootstrapped standard errors given in parentheses. The sample consists of 16094 firm-year observations from the Compustat database for 109 peer groups during the 1972 to 2015 period, resulting from sample selection criteria as outlined in section 3.1.1.Each parameter is identified by its corresponding model component in the following utility function:

$$
\begin{aligned}
& u_{i, t-1}^{j}=z_{i, t}^{j} k_{i, t}^{j}-I_{i, t}^{j}-\mathcal{I}_{I_{i, t}^{j}>0}\left(\phi_{I, 1}^{j} I_{i, t}^{j}+\phi_{I, 2}^{j}\left(\frac{I_{i, t}^{j}}{K_{i, t}^{j}}\right)^{2}\right)-\mathcal{I}_{e_{i, t}^{j}>0}\left(\phi_{e, 1}^{j} e_{i, t}^{j}\right)-\mathcal{I}_{p_{i, t}^{j}>0}\left(\phi_{p, 1}^{j} p_{i, t}^{j}\right) \\
& -\mathcal{I}_{A} \gamma_{p, 1}^{j} z_{i, t}^{j} k_{i, t}^{j}\left|\frac{p_{i, t}^{j}}{k_{i, t}^{j}}-\widetilde{\left(\frac{p}{k}\right)^{j}}\right|-\mathcal{I}_{B} \gamma_{p, 2}^{j} z_{i, t}^{j} k_{i, t}^{j}\left|\frac{p_{i, t}^{j}}{k_{i, t}^{j}}-\widetilde{\left(\frac{p}{k}\right)^{j}}\right|
\end{aligned}
$$

where $z_{i, t}^{j}$ if the profitability of firm $i$ in industry $j$ at time $t, k_{i, t}^{j}$ is capital, $I_{i, t}^{j}$ is investment, $e_{i, t}^{j}$ is external finance, $p_{i, t}^{j}$ is cash, and $\mathcal{I}_{A}$ is an indicator variable for condition $A$ being true. Peer parameters are denoted by $\gamma$ and intra-firm cost associated with external finance, cash and investment are denoted by $\phi$.

\begin{tabular}{cccccc}
\hline \multicolumn{2}{c}{ Peer Parameters } & \multicolumn{4}{c}{ Intra-firm Parameters } \\
$\gamma_{p, 1}^{j}$ & $\gamma_{p, 2}^{j}$ & $\phi_{e, 1}^{j}$ & $\phi_{p, 0}^{j}$ & $\phi_{I, 1}^{j}$ & $\phi_{I, 2}^{j}$ \\
\hline 0.36 & 0.80 & 0.074 & 0.097 & 0.053 & 333.1 \\
$(0.029)$ & $(0.021)$ & $(0.012)$ & $(0.0042)$ & $(0.0014)$ & $(13.81)$ \\
\hline \hline
\end{tabular}


Table 10: Structural Parameter Estimates Identified by the Assumption that Peer Effects Are Time-Invariant

This table contains estimates of the structural parameters of the model, with bootstrapped standard errors given in parentheses. The sample consists of 16094 firm-year observations from the Compustat database for 109 peer groups during the 1972 to 2015 period, resulting from sample selection criteria as outlined in section 3.1.1.Each parameter is identified by its corresponding model component in the following utility function:

$$
\begin{aligned}
& u_{i, t-1}^{j}=z_{i, t}^{j} k_{i, t}^{j}-I_{i, t}^{j}-\mathcal{I}_{I_{i, t}^{j}>0}\left(\phi_{I, 1}^{j}+\phi_{I, 2}^{j}\left(\frac{I_{i, t}^{j}}{K_{i, t}^{j}}\right)^{2}\right)-\mathcal{I}_{e_{i, t}^{j}>0}\left(\phi_{e, 1}^{j} e_{i, t}^{j}\right)-\mathcal{I}_{p_{i, t}^{j}>0}\left(\phi_{p, \xi^{T E D}}^{j} \xi_{i, t}^{T E D}\right) \\
& -\mathcal{I}_{A} \gamma_{p, 1}^{j}\left|\frac{p_{i, t}^{j}}{k_{i, t}^{j}}-\widetilde{\left(\frac{p}{k}\right)_{-i, t}^{j}}\right|-\mathcal{I}_{B} \gamma_{p, 2}^{j}\left|\frac{p_{i, t}^{j}}{k_{i, t}^{j}}-\widetilde{\left(\frac{p}{k}\right)_{-i, t}^{j}}\right|
\end{aligned}
$$

where $z_{i, t}^{j}$ if the profitability of firm $i$ in industry $j$ at time $t, k_{i, t}^{j}$ is capital, $I_{i, t}^{j}$ is investment, $e_{i, t}^{j}$ is external finance, $p_{i, t}^{j}$ is cash, $\mathcal{I}_{A}$ is an indicator variable for condition $A$ being true, and $\xi_{i, t}^{j}$ is a state variable for incentives to hold cash. Peer parameters are denoted by $\gamma$ and intra-firm cost associated with external finance, cash and investment are denoted by $\phi$. Panel B contains results for the main estimation that includes $\xi_{i, t}^{j}$, the state variable for incentives to hold cash not captured by the model, in addition to the other parameters also included in the specification as shown in Panel A.

\section{Panel A}

\begin{tabular}{cccccc}
\hline \multicolumn{3}{c}{ Peer Parameters } & \multicolumn{4}{c}{ Intra-firm Parameters } \\
$\gamma_{p, 1}^{j}$ & $\gamma_{p, 2}^{j}$ & $\phi_{e, 1}^{j}$ & $\phi_{p, \xi^{j E D}}^{j}$ & $\phi_{I, 1}^{j}$ & $\phi_{I, 2}^{j}$ \\
\hline 0.78 & 0.51 & 0.52 & 1.55 & -0.016 & 46.88 \\
$(0.065)$ & $(0.049)$ & $(0.026)$ & $(0.0146)$ & $(0.0006)$ & $(5.75)$ \\
& & & & & \\
\hline \hline
\end{tabular}




\section{Table 11: Interpreting the Magnitude of Peer Effects}

This table contains median and average simulated cash holdings from a discrete-time investment model as described in Section 4.7. In Panel A there is no strategic interaction between firms, while in Panel B firms have costs of deviating from the median cash level as described in section 4.7. For each panel I solve the model numerically, and simulate data based on the model solution. In Panel $\mathrm{B}$, the state space is too large to perform a traditional value function iteration, or similar methods, so the model is solved assuming an oblivious equilibrium approach, with further details given in Section 4.7.

Panel A: Utility Function Without Peer Effects

\begin{tabular}{cccc}
\hline Firm & $\phi_{e}$ & Median Cash & Mean Cash \\
\hline 1 & 0.06 & 0 & 0.1895 \\
2 & 0.08 & 0.0639 & 0.2311 \\
3 & 0.10 & 0.1040 & 0.2432 \\
4 & 0.12 & 0.1277 & 0.2840 \\
5 & 0.14 & 0.1277 & 0.2965 \\
All & & 0.0751 & 0.2489
\end{tabular}

Panel B: Utility Function With Peer Effects

\begin{tabular}{cccc}
\hline Firm & $\phi_{e}$ & Median Cash & Mean Cash \\
\hline 1 & 0.06 & 0.1 & 0.0931 \\
2 & 0.08 & 0.1 & 0.0938 \\
3 & 0.10 & 0.1 & 0.0985 \\
4 & 0.12 & 0.1 & 0.0968 \\
5 & 0.14 & 0.1 & 0.0987 \\
All & & 0.104 & 0.0962 \\
\hline \hline
\end{tabular}


Figure 1: Kernel-Weighted Local Polynomial Regression of Marginal Values of Cash on Time

This figure shows the evolution of marginal values of cash through time by plotting estimated values from a kernel-weighted (epanechnikov) local polynomial regression of estimated marginal values of cash, estimated using a modified version of the Faulkender and Wang (2006) as explained in Section 3.2, on time.

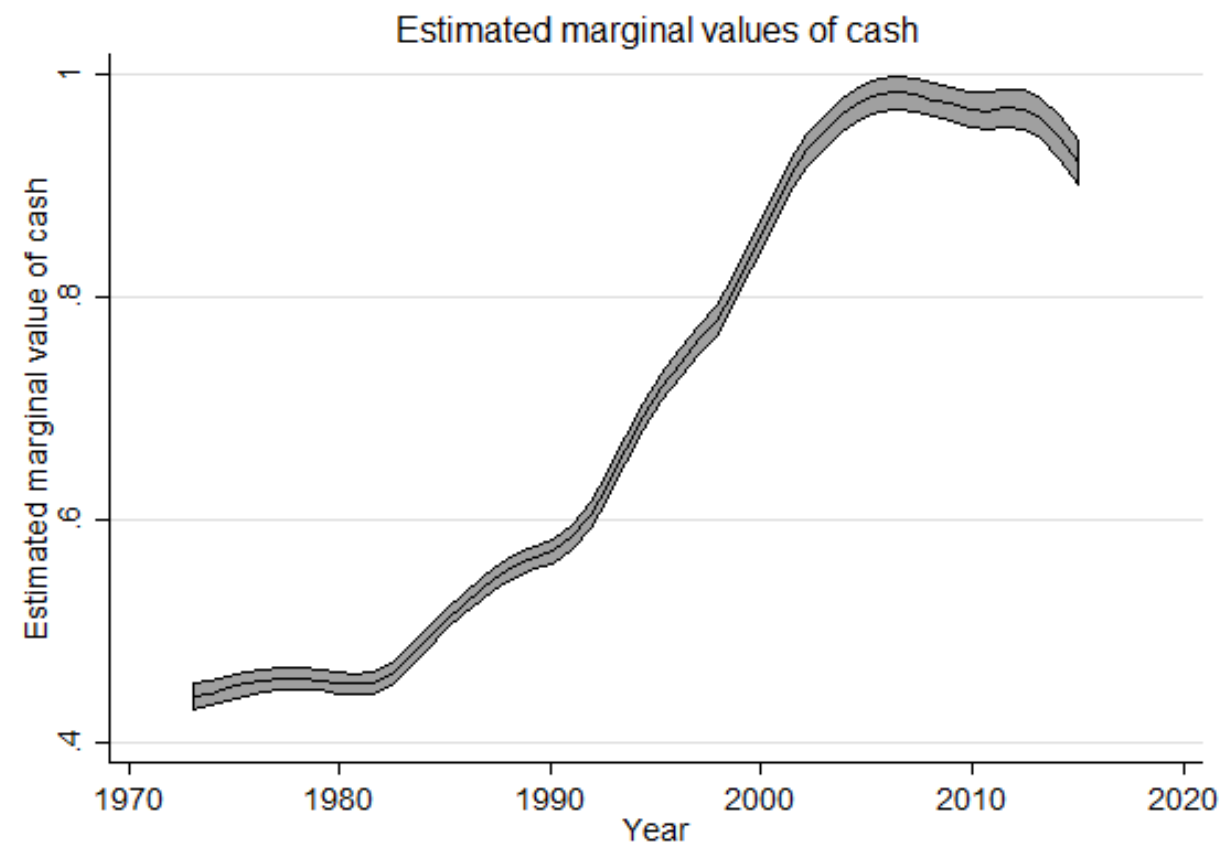




\section{Figure 2: Persistence of Cash Incentive Shocks}

This figure shows the distribution of estimated cash incentive shocks across peer groups. A modified version of the Faulkender and Wang (2006) method is used to obtain firm-level estimates of marginal values of cash, whose residual component after purging out the variation explained by model state variables, is estimated using the Bajari et al. (2012) method. The properties of the associated time series processes of the residual incentives to hold cash for the peer groups used in this study are summarized in this table by their respective $\mathrm{AR}(1)$ coefficients. The estimation procedure is described in Section 3.2.

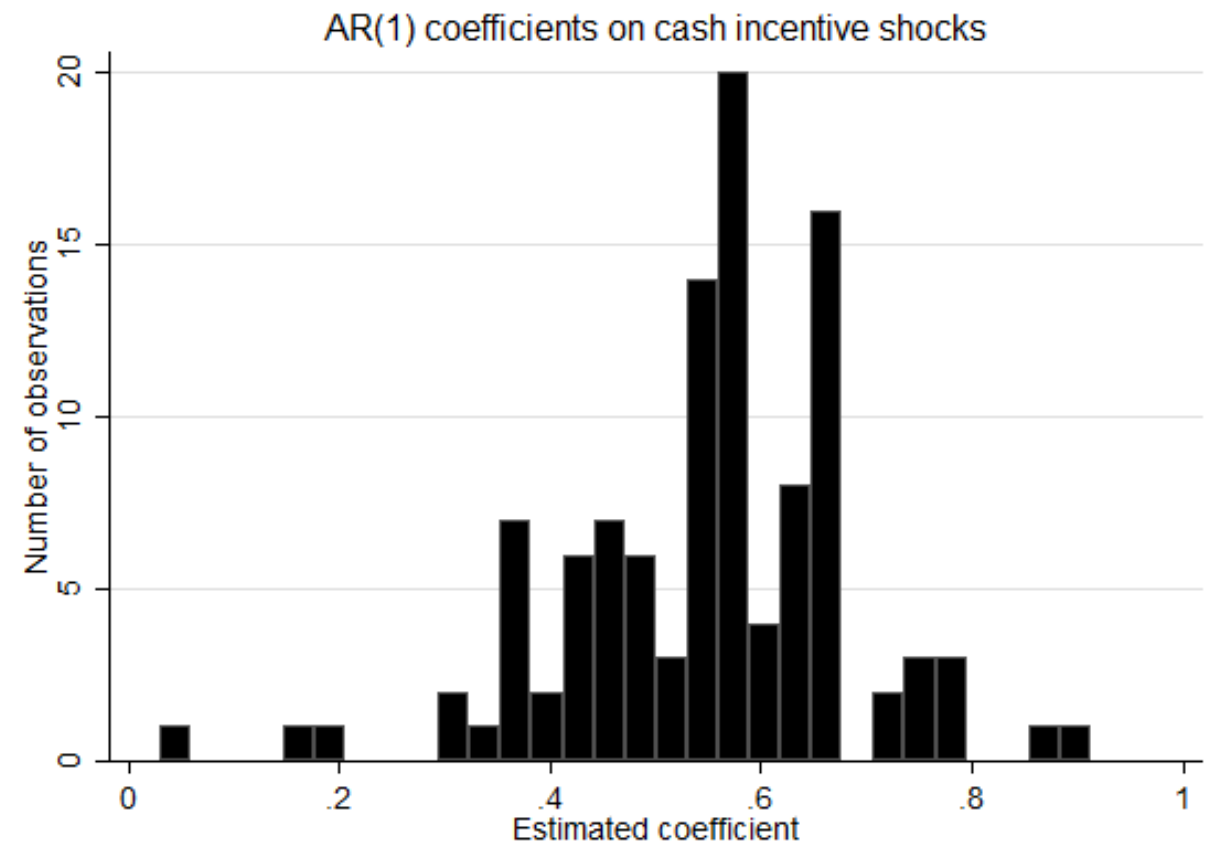




\section{Figure 3: Policy Function for Investment}

This figure shows plots of the policy function for investment, i.e. the choice of investment for different values of the state variables as predicted by the policy function estimated for policy groups I and II as described in Section 3.2.1. For each state variable, the plots are generated by averaging over latent classes, holding other state variables constant at their average values.
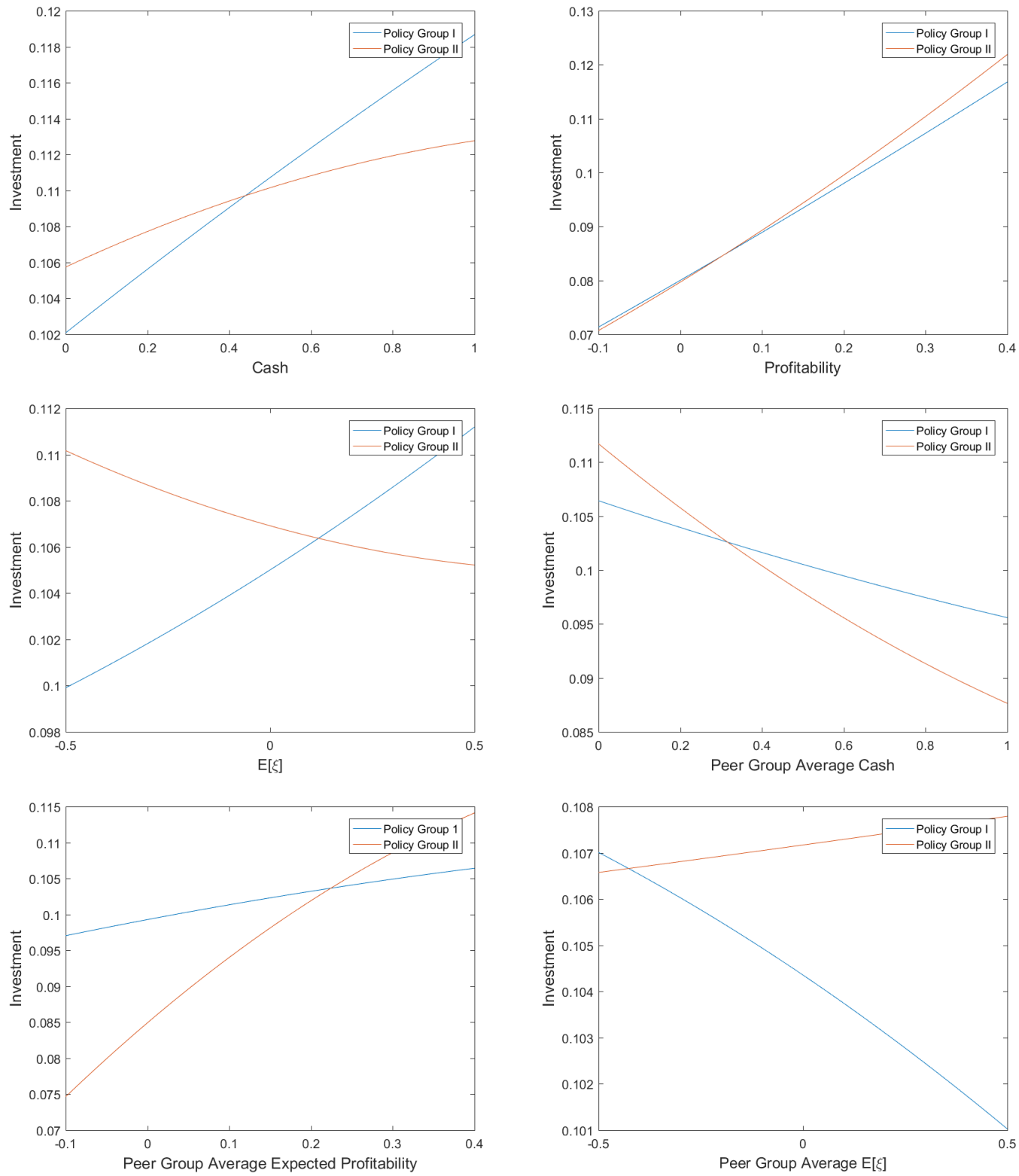


\section{Figure 4: Policy Function for External Finance}

This figure shows plots of the policy function for external finance, i.e. the choice of external finance for different values of the state variables as predicted by the policy function estimated for policy groups I and II as described in Section 3.2.1. For each state variable, the plots are generated by averaging over latent classes, holding other state variables constant at their average values.
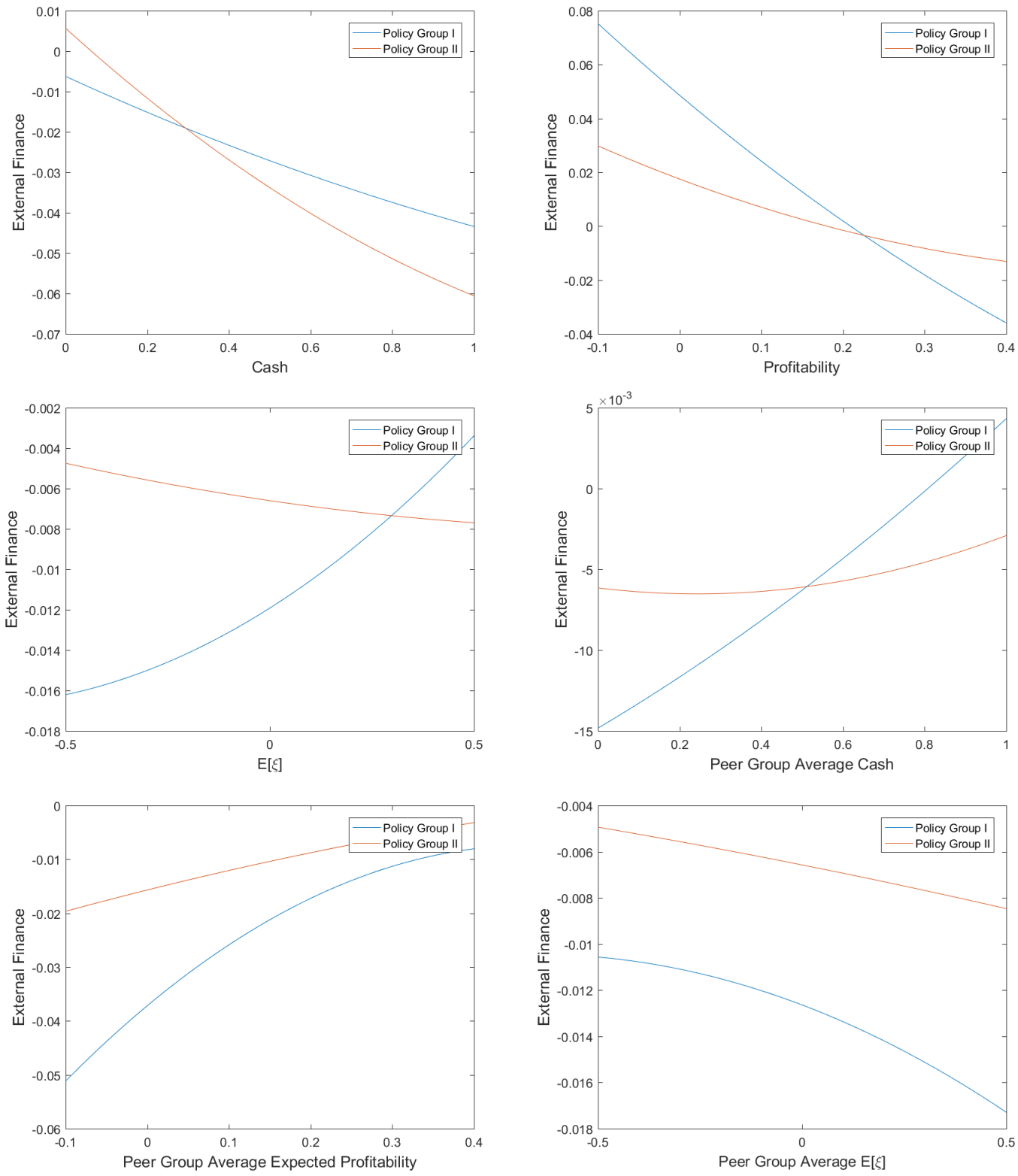


\section{Figure 5: An Example of the Response to Shocks to Peer Cash Holdings}

This figure shows plots of the response to a shock to peer firm cash holdings. In particular, a random peer group-year with four firms is chosen, where firms one, two, three and four have initial capital (cash) levels equal to $16.73(0.21), 35.20(0.26), 177.15(0.05)$ and $14.83(0.05)$. In Panel A, firms are given average values of profitability, and after reaching the subsequent steady state values of cash holdings, firms three and four are given a positive shock of $100 \%$ to cash holdings, defining event time equal to zero. Panels B and $\mathrm{C}$ show similar responses to shocks equal to one full-sample standard deviation of cash holdings and one firm-level standard deviation of simulated cash holdings, respectively. The subsequent effect on peer group cash holdings for event years -10 to 70 , inclusive, is shown in this figure, where the main emphasis is on the reaction of firms one and two.

Panel A: 100\% Increase In Cash Holdings
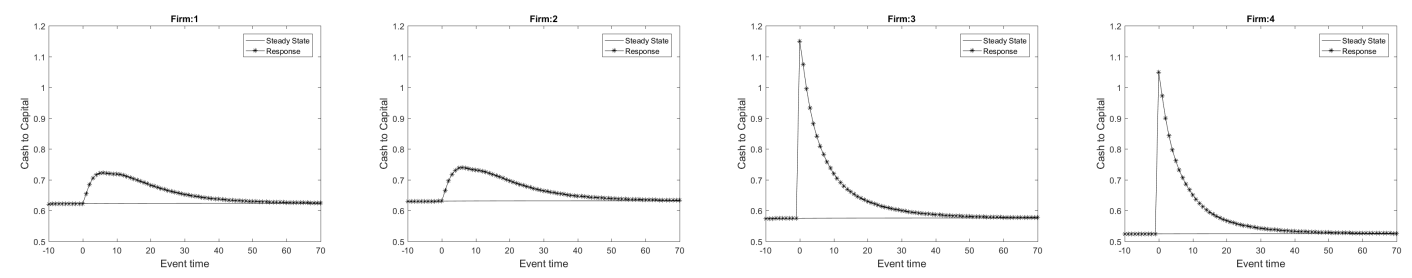

Panel B: One Full-Sample Standard Deviation Increase In Cash Holdings
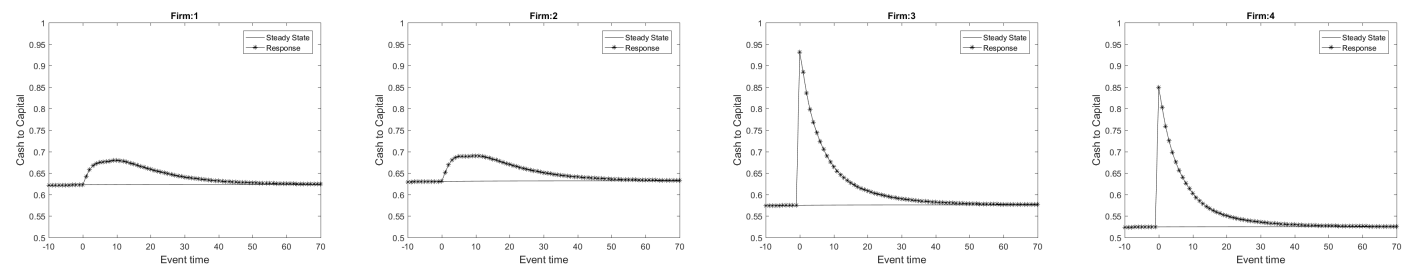

Panel C: One Firm-Level Standard Deviation Increase In Cash Holdings
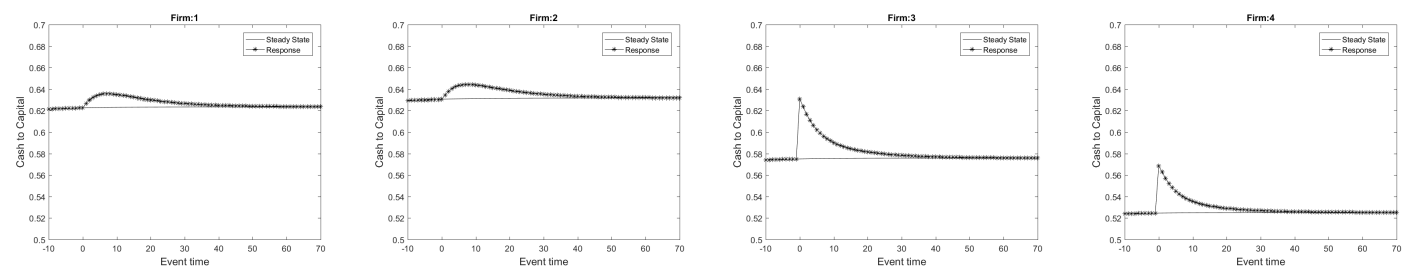